\title{
Comparación de la digestibilidad de tres especies forrajeras estimada mediante diferentes técnicas
}

\author{
Comparison of the digestibility of three forage species estimated \\ by different techniques
}

\section{Comparação da digestibilidade de três espécies forrageiras estimadas por diferentes técnicas}

\author{
César A. Navarro-Ortiz ${ }^{1 *}$, María L. Roa-Vega ${ }^{2}$ \\ 1 Médico Veterinario Zootecnista, MSc; \\ 2 Zootecnista, MSc. PhD; \\ * Escuela de Ciencias Animales. Facultad de Ciencias Agropecuarias y Recursos Naturales, Grupo de Investigación en \\ Agroforestería, Universidad de los Llanos, Villavicencio-Meta, Colombia \\ Email: cesar.navarro@unillanos.edu.co
}

Recibido: 28 de septiembre de $2017 \quad$ Aceptado: 29 de mayo de 2018

\begin{abstract}
Resumen
Esta investigación se realizó en el municipio de Villavicencio, en la Universidad de los Llanos, cuyo objetivo fue determinar la digestibilidad de tres forrajes para bovinos mediante cuatro técnicas diferentes: una in situ y tres in vitro (inoculación con líquido ruminal, producción de gas, y enzimática) con el fin de validar las técnicas y los equipos que se están usando para estos procedimientos; se evaluaron las especies forrajeras y arbóreas: Pennisetum purpureum (PP), Hibiscus rosa-sinensis (HR) y Gliricidia sepium (GS), además se valoró en todas las técnicas, la curva y tasa de degradación de la materia seca (MS), fibra detergente neutro (FDN) y proteína cruda (PC) (0 a 72 horas). Se utilizó un diseño completamente al azar con arreglo de medidas repetidas, bajo el cual se realizó el análisis de varianza para determinar los rangos de desviación entre las técnicas y así establecer la tendencia de los datos; las variables evaluadas fueron las digestibilidades de la MS, FDN y PC de los tres forrajes de las cuatro técnicas; luego de verificar las diferencias entre las varianzas de las digestibilidades, y comprobar el supuesto de esfericidad con el test de Mauchly, se realizó la comparación múltiple con la prueba de Bonferroni. La digestibilidad de la MS, FDN y PC varió entre 39.89-44.22, 54.18-64.26 y 47.54-57.05\%; 79.29-84.18, 76.3086.95 y $72.81-89.03 \% ; 32.52-62.14,69.12-76.52$ y $42.00-66.54 \%$ respectivamente en los forrajes PP, HR y GS, en función de la técnica empleada para su estimación. A pesar de encontrar diferencias estadísticamente significativas entre varias de las comparaciones realizadas en las técnicas de digestibilidad, se encontró un alto coeficiente de determinación y alta correlación entre las estimaciones in vitro: inoculación con líquido ruminal, producción de gas y enzimática con respecto a la estimación in situ.
\end{abstract}

Palabras clave: Arbustos, digestión, forrajes cultivados, nutrimentos, suplementación nutricional. 


\begin{abstract}
This research was conducted in the Villavicencio city, at the Universidad de los Llanos, whose objective was to determine the digestibility of three forages for cattle through four different techniques: one in situ and three in vitro (inoculation with ruminal fluid, gas production, and enzymatic), in order to validate the techniques and equipment that are being used for these procedures; the forage species were evaluated: Pennisetum purpureum, Hibiscus rosa-sinensis y Gliricidia sepium, in addition it was evaluated both in all techniques: the curve and rate of degradation of dry matter (DM), neutral detergent fiber (NDF) and crude protein (PC) (0 to 72 hours). A repeated measures design was used, under which the analysis of variance was performed to determine the ranges of deviation between the techniques and thus establish the trend of the data; the variables evaluated were the digestibilities of DM, NDF and PC of the three forages of the four techniques; after verifying the differences between the variances of the digestibilities, and check the assumption of sphericity with the Mauchly test, the multiple comparison was performed with the Bonferroni test. The digestibility of DM, NDF and PC varied between 39.89-44.22, 54.18-64.26 and 47.54-57.05\%; 79.29-84.18, 76.30-86.95 and 72.81-89.03\%; 32.52-62.14, 69.1276.52 and $42.00-66.54 \%$ respectively in the PP, HR and GS forages, depending on the technique used for their estimation. Despite finding statistically significant differences among several of the comparisons made in the techniques of digestibility, it was found a high determination coefficient and correlation between estimates in vitro: inoculation with ruminal fluid, gas production and enzymatic with respect to the in situ estimate.
\end{abstract}

Key words: Shrubs, digestion, cultivated forages, nutrients, nutritional supplementation.

\title{
Resumo
}

Esta pesquisa foi realizada na cidade de Villavicencio, na Universidad de los Llanos, cujo objetivo foi determinar a digestibilidade de três forragens em bovinos através de quatro técnicas in vitro diferentes: um in situ e três in vitro (inoculação com fluido ruminai, produção de gás, e enzimática), com a fim de validar as técnicas e equipamentos que estão sendo usados para estes procedimentos; foram avaliadas espécies forrageiras e árvore: Pennisetum purpureum (PP), Hibiscus rosa-sinensis (HR) y Gliricidia sepium (GS), além disso foi avaliado em todas as técnicas: curva e a taxa de degradação de matéria seca (MS), fibra em detergente neutro (FDN) e proteína bruta (PB) (0 a 72 horas). Utilizou-se um desenho de medidas repetidas, sob as quais foi realizado o análise de variância para determinar as gamas de desvio entre as técnicas e assim estabelecer a tendência dos dados; as variáveis avaliadas foram a digestibilidade da MS, FDN e PB dos três forragens das quatro técnicas; depois de verificar as diferenças entre as variâncias de digestibilidade, e verificar a hipótese de esfericidade com o teste de Mauchly, foi realizado a comparação múltipla com o teste de Bonferroni. A digestibilidade de MS, FDN e PB variou entre 39,89-44,22, 54,18-64,26 e 47,54-57,05\%; 79,29-84,18, 76,30-86,95 e 72,81-89,03\%; 32,52-62,14, 69,12-76,52 e 42,00$66,54 \%$, respectivamente nas forragens PP, HR e GS, dependendo da técnica utilizada para sua estimação. Apesar de encontrar diferenças estatisticamente significativas entre varios das comparações realizadas nas técnicas de digestibilidade, foi encontrado un alto coeficiente de determinação y uma elevada correlação entre as estimativas in vitro: inoculação líquido ruminal, produção de gás e enzimática com respeito à estimativa in situ.

Palavras chave: Arbustos, digestão, forragens cultivadas, nutrientes, suplementos nutricionais.

\section{Introducción}

La producción animal en la zona del Piedemonte llanero se caracteriza por marcadas fluctuaciones en la cantidad y calidad de los forrajes, que traen como consecuencia baja productividad (Rincón et al., 2010). Esto hace que sea necesario evaluar, en el laboratorio como primera medida, germoplasmas de forrajes adaptados y de buena calidad, que provean mayores aportes nutricionales, como es el caso de las especies arbóreas y arbustivas que están presentes en el trópico como una alternativa para la alimentación de los sistemas de producción bovina; los forrajes arbustivos pueden reemplazar completamente los alimentos balanceados fabricados con cereales y tortas oleaginosas, sin reducir la calidad ni la cantidad de producto animal, y por tanto, permitir niveles muy altos de intensificación, sin generar una dependencia de insumos externos (Valencia et al., 2010). Esto es debido a que en la producción animal es muy importante la eficien- cia con la que son utilizados los alimentos, si se tiene en cuenta que por lo regular abarcan el 70 a $80 \%$ de los costos de producción (Duarte et al., 2000).

Desde otra perspectiva, el consumo y la digestibilidad han sido áreas de gran interés para los nutricionistas, puesto que en producción animal es importante la eficiencia en el uso de dietas balanceadas para que el animal exprese su potencial productivo, por lo tanto el conocimiento de la calidad nutricional de los alimentos es básico para proporcionar los nutrientes requeridos de acuerdo a su estado fisiológico y productivo (leche o carne) (Uffo, 2011). No solamente el conocimiento del valor nutritivo de los alimentos es fundamental sino que también, es necesario considerar los efectos de los procesos de digestión, absorción y metabolismo animal (Sosa et al., 2006). Al respecto conviene decir que, la calidad nutritiva de los forrajes está en función de la proporción y el nivel de consumo, de la digesti- 
bilidad, del contenido de nutrientes y la eficiencia con que estos pueden ser metabolizados y utilizados por los animales (Giraldo et al., 2007).

Ahora bien, los alimentos que más varían en digestibilidad de la materia seca, son los forrajes, debido principalmente a la madurez de la planta. Asimismo se debe tener en cuenta que existen diversas etapas productivas de los animales, que muestran hábitos y requerimientos alimenticios diferentes, afectando su digestibilidad (Estupiñán et al., 2007). Dentro de la evaluación de la calidad de los recursos forrajeros, el principal parámetro que la define es la digestibilidad de la materia seca, que junto con la cantidad de fibras detergentes neutra y acida, y proteína bruta, constituyen la información necesaria para valorar los forrajes que son suministrados en la dieta de los bovinos. Podría decirse que la calidad es una propiedad del forraje, pero que puede variar como resultado de la respuesta del forraje al ambiente y/o manejo, y que además debe considerarse otros factores como la respuesta animal, consumo y digestión del mismo; por lo tanto conocer la digestibilidad de la materia seca, fibra detergente neutra y proteína cruda, permite por un lado ofrecer dietas a los animales que tengan mayor probabilidad de suplir sus requerimientos, y por otro lado, clasificar los forrajes más utilizados en la producción, ya que se considera que un forraje tiene alta calidad cuando tiene aproximadamente $70 \%$ de digestibilidad in vitro de la materia seca (DIVMS), menos de 50\% de fibra detergente neutra (FDN) y más de $15 \%$ de proteína bruta (PB); y por el contrario, en uno de baja calidad la DIVMS disminuye a menos del 50\%, la FDN sube a más del 65\% y la PB baja a menos del 8\% (Cardozo, 2013).

Los métodos in vitro para estimar la digestibilidad de forrajes en bovinos, que han sido utilizados más ampliamente desde su introducción son el de Tilley y Terry, y el de Van Soest, los cuales consisten en someter los forrajes a la acción directa de los microorganismos ruminales, y son considerados los procedimientos más exactos para la predicción de la digestibilidad en rumiantes. El método de Tilley y Terry se considera un método referente para calcular la digestibilidad en alimentos para rumiantes, el cual ha sido modificado y adaptado según el tipo de alimento a analizar, al igual que se han desarrollado y probado diferentes tampones de dilución para ajustar el pH del inóculo (Giraldo et al., 2007). Pese a su exactitud y a todas las modificaciones y adaptaciones, este método sigue siendo un procedimiento que consume mucho tiempo y trabajo, además cada alimento debe incubarse por separado, limitando el número de muestras a ser analizadas por corrida o tanda.
Las primeras pruebas de degradabilidad utilizando la técnica in vitro por producción de gas (TIVPG) se realizaron en la Estación Experimental Weende en la Universidad de Goettingen en Alemania en 1860. La TIVPG es similar a cualquier técnica de digestibilidad in vitro, en donde los sustratos son molidos y mezclados en un medio anaerobio con un inóculo de población microbiana tomado del rumen. La medición de producción de gas (PG) ha tenido relevancia en los últimos años, de tal modo que existen varias metodologías (Muro, 2007). Hay TIVPG desarrolladas para la evaluación de la calidad del alimento bajo dos criterios para medir los volúmenes de gas: (1) el gas medido colectado a presión atmosférica y su volumen es determinado directamente o (2) el gas acumulado medido en un contenedor con un volumen fijo, y el volumen es calculado a partir de los cambios de presión. Las técnicas de gas disponibles son: (a) el método de gas Hohenheim o el método de Menke (Menke et al., 1979) (jeringas donde el émbolo es empujado debido al gas producido); (b) el sistema de desplazamiento de líquidos (Beuvink et al., 1992) (botellas con $60 \mathrm{ml}$ de líquido ruminal bufferizado conectada al sistema de desplazamiento de agua); (c) método manométrico (Waghorn y Stafford, 1993) (frascos de $250 \mathrm{ml}$ conectados al dispositivo); (d) sistemas de transductor de presión: manual (Theodorou et al., 1994), computarizado (Pell y Schofield, 1993) (media de la presión dentro de la botella sellada), y la combinación del transductor de presión y el sistema de liberación de gas (Davies et al., 2000) (Davies et al., 2000).

Debido a que la determinación de la digestibilidad in vivo en bovinos es poco práctica, se han desarrollado métodos de laboratorio que simulan los procesos de digestión, por lo cual muchos intentos se han realizado para establecer técnicas simples para determinar la digestibilidad de alimentos para rumiantes, uno de ellos cuyo objetivo es reemplazar el líquido ruminal, se basa en el uso de enzimas comerciales con el fin de reproducir la actividad celulolítica que presentan los microorganismos ruminales. Se han realizado estudios empleando la preparación con enzimas comerciales, siendo importante en esta técnica que el material sea preparado de una manera determinada para que la enzima sea capaz de penetrar y reaccionar con el sustrato (Arce et al., 2003).

Existen actualmente restricciones que manejan las comisiones de ética de los organismos internacionales de investigación para el uso de animales experimentales, aunque debe precisarse que en Colombia, ésta reglamentación es precaria e imprecisa (Resolución 8430 de 1993; Ley 84 de 1989) (De Osorio, 2006; Concepción et al., 2007; Botero y Gómez, 2013); los investiga- 
dores consientes del bienestar animal, han trabajado métodos que permitan obviar el uso de animales cánulados para realizar pruebas de digestibilidad, siendo la técnica pepsina-celulasa (enzimática) una de ellas, la cual es recomendable por eliminar variaciones entre corridas, aunque es un poco costosa y además puede presentar una considerable variación en la actividad enzimática de una fuente comercial a otra, tiene la ventaja de ser completamente independiente del animal, por lo cual se presenta una menor variación (Ruiz, 2011).

Se han utilizado enzimas derivadas de las celulasas de Trichoderma viridae y Aspergillus niger con el pH ajustado a 4.8; moliendo la muestra y pasándola a través de una criba de $0.75 \mathrm{~mm}$, posteriormente el residuo es colectado, secado y pesado, y consecutivamente se determina el porcentaje de materia seca digestible (Vega, 2016). También se han probado diferentes concentraciones de celulasa, observándose que una alta cantidad de enzima podría resultar en una mejor descomposición del material celulolítico y dar valores de correlación más cercana con los de digestibilidad in vivo (Arce et al., 2003; Torres et al., 2009). Esta técnica enzimática ha sido probada para ensilajes, pastos secos y cereales considerando que los resultados de estas mediciones son eficientes (González, 2016; Sainz, 2016).

Por otro lado, la retención de los forrajes dentro del rumen provee suficiente tiempo a los microorganismos para degradar eficientemente los alimentos ingeridos (Araujo y Vergara, 2007). Se ha podido observar que el tiempo de retención en el rumen está entre 48 y 60 horas, y que éste influye en el valor alimentario, especialmente la degradabilidad, la cual es esencial para optimizar el nitrógeno y la energía disponible para la síntesis de proteína microbiana en el rumen (Bulang et al., 2008). Por este motivo se analizó y comparó mediante cuatro técnicas diferentes, la digestibilidad de tres forrajes a las $0,6,12,24,48$ y 72 horas, para determinar la curva de la degradabilidad de los mismos, y poder establecer si los resultados de la digestibilidad in vitro son similares a los determinados mediante la técnica in situ o si muestran algún rango de desviación.

\section{Materiales y Métodos}

\section{Ubicación}

Esta investigación se realizó en el municipio de Villavicencio, en la granja y laboratorios de la Universidad de los Llanos sede Barcelona, ubicada en el kilómetro 12 vía Puerto López, con una altitud de 465 metros sobre el nivel del mar, temperatura promedio de $27^{\circ} \mathrm{C}$ y precipitación anual entre 1900 y 3250 milímetros (IDEAM, 2014).

\section{Muestreo de forrajes}

Las muestras de hojas de los forrajes fueron recolectadas de las parcelas de la Universidad, a una edad de rebrote de 60 días, luego fueron deshidratadas en una estufa de aire forzado MEMMERT ${ }^{\circledR}$ (Schwabach, Baviera, Alemania) a $68{ }^{\circ} \mathrm{C}$ por un tiempo de 72 horas y posteriormente molidas y tamizadas en una criba de $1 \mathrm{~mm}$ para garantizar su homogeneidad en el tamaño de la partícula; a los forrajes secos Pennisetum purpureum, Hibiscus rosa-sinensis y Gliricidia sepium se les realizó un análisis nutricional preliminar, en el cual se les determinó materia seca (MS) por desecación, proteína cruda (PC) por el método Kjeldahl usando el factor $N$ x 6.25 y fibra detergente neutro (FDN), tres repeticiones por forraje, esto con el fin de conocer su caracterización nutricional (AOAC, 2005) (Tabla 1).

\section{Digestibilidad in situ}

Se utilizó la técnica con bolsas de nylón (Mertens, 2002), con tamaño de 20 x $10 \mathrm{~cm}$ con un poro promedio de 50 micras, las cuales se secaron previamente a $60^{\circ} \mathrm{C}$ por 24 horas con el fin de llevarlas a peso constante y en cada una se colocaron $8 \mathrm{~g}$ de materia seca de cada arbusto o forraje por tres repeticiones en cada hora $(0,6,12,24,48$ y 72$)$, es decir que se inocularon 18 bolsas por forraje para un total de 54 bolsas, las cuales fueron colocadas en la porción ventral del rumen, dejándoles cierta libertad de movimiento; para sostenerlas fueron amarradas a una cadena conservando una distancia entre la cánula y las primeras bolsas de $50 \mathrm{~cm}$; estas fueron colocadas en forma secuencial, y extraídas de acuerdo a la hora correspondiente de degradación; su lavado fue uniforme hasta retirar todos los residuos del rumen (Figura 1), tras lo cual fueron secadas en estufa de aire forzado a $68{ }^{\circ} \mathrm{C}$, para posteriormente determinar contenido de MS, FDN y PC, y estimar así su digestibilidad.

Tabla 1. Contenido (\%) de proteína cruda (PC) y fibra detergente neutro (FDN) en los forrajes

\begin{tabular}{|l|c|c|}
\hline \multirow{2}{*}{\multicolumn{1}{|c|}{ FORRAJE }} & \multicolumn{2}{c|}{ Nutrientes (\%) } \\
\cline { 2 - 3 } & FDN & PC \\
\hline Pennisetum purpureum & 42.9 & 9.2 \\
\hline Hibiscus rosa-sinensis & 81.8 & 17.3 \\
\hline Gliricidia sepium & 63.8 & 23.6 \\
\hline
\end{tabular}




\section{Digestibilidad in vitro inoculación líquido ruminal}

Estas pruebas fueron realizadas en el Laboratorio de Nutrición Animal. Para ello 0.2 g de MS de cada forraje se colocaron en jeringas desechables de $20 \mathrm{ml}$ que contenían $20 \mathrm{ml}$ de una mezcla de saliva de McDougall previamente gasificada con $\mathrm{CO}_{2}$, y liquido ruminal en una proporción 2 a 1, las cuales se sellaron y se colocaron en una incubadora HEIDOLPH Inkubator $1000^{\circledR}$ (Schwabach, Baviera, Alemania) por triplicado para cada tiempo de incubación (18 muestras por forraje por 3 forrajes $=54$ muestras). El líquido ruminal se obtuvo de la planta de beneficio a partir de animales alimentados con pastos del género Brachiaria spp.; la solución buffer (saliva de McDougall) fue preparada mezclando en un litro de agua destilada $9.8 \mathrm{~g}$ de bicarbonato de sodio $\left(\mathrm{NaHCO}_{3}\right), 9.3 \mathrm{~g}$ de fosfato de sodio $\left(\mathrm{Na}_{2} \mathrm{PO}_{4}\right), 0.57 \mathrm{~g}$ de cloruro de potasio $(\mathrm{KCl}), 0.47 \mathrm{~g}$ de cloruro de sodio $(\mathrm{NaCl}), 0.04 \mathrm{~g}$ de cloruro de calcio $\left(\mathrm{CaCl}_{2}\right)$ y $0.06 \mathrm{~g}$ de cloruro de magnesio $\left(\mathrm{MgCl}_{2}\right)$ (Gómez et al., 2013) (Figura 2). Después de la incubación, el contenido de las jeringas se filtró en un embudo con papel filtro de $150 \mathrm{~mm}$ WHATMAN ${ }^{\circledR}$ (Maidstone, Kent, Reino Unido), y se lavó con 500 ml de agua destilada a temperatura ambiente con el fin de detener el proceso. El residuo fue puesto a secar en estufa de aire forzado a $68^{\circ} \mathrm{C}$ durante 72 horas, para luego determinar el contenido de MS, FDN y PC, y con ello poder estimar su digestibilidad.

\section{Digestibilidad in vitro producción de gas}

Estas pruebas también fueron realizadas en el Laboratorio de Nutrición Animal. Para ellos se siguieron los mismos procedimientos que se siguieron a los descritos para la digestibilidad in vitro con liquido ruminal, solo que, en este caso, se midió la producción de gas mediante el desplazamiento del embolo de jeringas de $50 \mathrm{ml}$, y posteriormente por medio de una ecuación dada por una regresión lineal se determinó la digestibilidad del forraje a partir del volumen de gas producido (Figura 3).

\section{Digestibilidad in vitro enzimática}

En el método enzimático se utilizaron 90 mg de la enzima celulasa proveniente del hongo Aspergillus niger (EC 3.2.1.4) (SIGMA CHEMICAL ${ }^{\circledR}$, St Louis, Missouri, Estados Unidos), $38 \mathrm{ml}$ de buffer acetato ( $\mathrm{pH} 4.8$ ), $2 \mathrm{ml}$ ácido clorhídrico y 140 mg de pepsina (EC 232-629-3) (AMRESCO $^{\circledR}$, Fountain Parkway Solon, Ohio, Estados Unidos) diluida en $2 \mathrm{ml}$ de buffer, mezclado con 200 mg de forraje (Arce et al., 2003). El inoculo fue colocado en tubos de ensayo de $30 \mathrm{ml}$ y mantenidos a temperatura constante $\left(39.2{ }^{\circ} \mathrm{C}\right)$ (Figura 4). Para cada tiempo de digestibilidad el procedimiento estuvo divi- do en dos pasos: la primera mitad del tiempo se realizó la incubación con pepsina diluida en $18 \mathrm{ml}$ de buffer acetato y $2 \mathrm{ml}$ de ácido clorhídrico (20 ml de solución) para posteriormente ser filtrado con papel filtro de 150 mm WHATMAN ${ }^{\circledR}$ (Maidstone, Kent, Reino Unido), y la otra mitad del tiempo se realizó la incubación con 20 $\mathrm{ml}$ de solución de celulosa (140 mg de celulosa diluida en $20 \mathrm{ml}$ de buffer acetato). Las muestras fueron incubadas al mismo tiempo, y se fueron extrayendo a la hora correspondiente $(0,6,12,24,48$, y 72 horas), tras lo cual, el contenido de los tubos se filtró de la misma manera mencionada anteriormente y lavó con $500 \mathrm{ml}$ de agua destilada a temperatura ambiente con el fin de detener el proceso. El procedimiento fue realizado en un baño de agua (MEMMERT ${ }^{\circledR}$, Schwabach, Baviera, Alemania) en el Laboratorio de Nutrición del Instituto de Acuicultura de los Llanos, adscrito a la Universidad de los Llanos.

Para todas las estimaciones in vitro (inoculación con líquido ruminal, producción de gas y enzimática), en cada análisis, además de los forrajes se incubaron dos tubos y/o jeringas con inóculo pero sin forraje (blanco) y dos con paja de avena (testigo) de digestibilidad in vitro conocida (61\% DIVMS) utilizada rutinariamente como estándar. Finalmente, la digestibilidad se calculó como el porcentaje de la diferencia entre la MS incubada y el residuo después del procedimiento correspondiente (in situ o in vitro inoculación líquido ruminal, producción de gas o enzimática); posteriormente al residuo se le estimó la cantidad de fibra detergente neutra (FDN), mediante el digestor de fibras, utilizando la solución FDN a $100^{\circ} \mathrm{C}$ durante 60 minutos y secado el residuo a $72^{\circ} \mathrm{C}$ durante 48 horas en una estufa de aire forzado, e igualmente la proteína cruda (PC) fue determinado por el método Kjeldahl usando el factor $\mathrm{N} \times 6.25$.

\section{Diseño experimental}

Con la información obtenida se estableció la curva y tasa de degradación de la MS, PC y FDN desde las 0 hasta las 72 horas, de cada uno de los tres forrajes, en los cuatro procedimientos: $\mathrm{P}_{1}$ in situ, $\mathrm{P}_{2}$ in vitro con liquido ruminal, $\mathrm{P}_{3}$ in vitro producción de gas y $\mathrm{P}_{4}$ in vitro enzimático con pepsina y celulasa. Para establecer la degradación efectiva de la MS, FDN y PC (P) se utilizó el modelo matemático, basado en la ecuación lineal de orden cero de Orskov y McDonald (1979):

$$
P=a+b\left(1-\exp ^{-c t}\right)
$$

Siendo $a$ = intercepto inicial (fracción soluble), $b=$ la fracción insoluble (potencialmente degradable), $c=$ tasa de degradación de $b$, y $t$ = tiempo de degradación. 


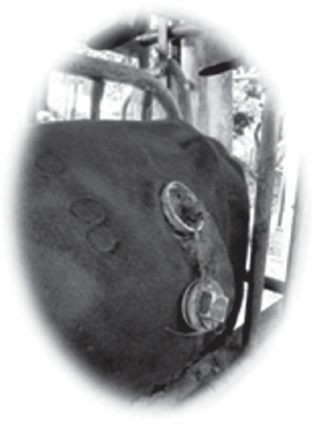

Figura 1. Bovino con cánula ruminal y bolsas en el rumen (Digestibilidad in situ)

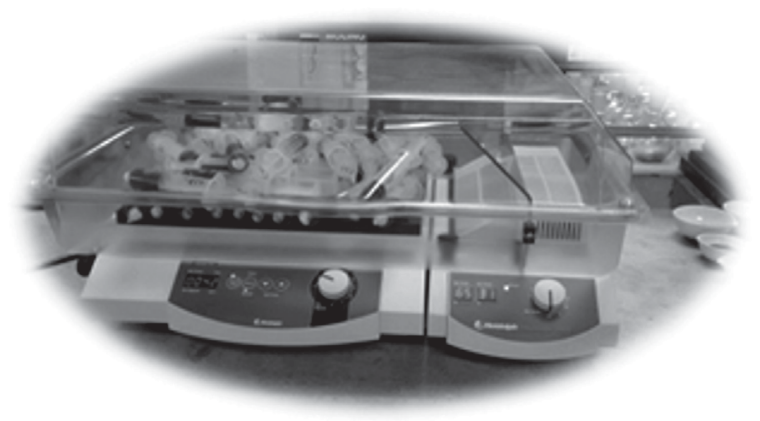

Figura 3. Jeringa con contenido gaseoso posterior al procedimiento

(Producción de gas)

El diseño estadístico fue uno de medidas repetidas bajo el modelo mixto con efectos principales por tiempo y método, los factores intra-sujetos fueron el tiempo de digestibilidad, la técnica para su estimación (procedimiento) y la interacción entre ambos, y el factor intersujeto fue el nutriente estudiado (MS, FDN y PC); las variables aleatorias fueron las digestibilidades de MS, FDN y PC, y la variable de efectos fijos fue la técnica de digestibilidad (in situ e in vitro: inoculación con líquido ruminal, producción de gas y enzimática). Adicionalmente se realizó una regresión lineal para analizar la relación entre las variables digestibilidad de la MS, FDN y PC in situ y digestibilidad de la MS, FDN y PC in vitro, a través de ecuaciones, y así poder estimar la primera a partir de las segundas. Los datos se analizaron bajo el siguiente modelo matemático:

$$
\gamma i j=\mu+\alpha i+\beta j+\varepsilon i j
$$

Dónde: $\gamma i j=$ es la variable aleatoria que mide la respuesta del sujeto experimentado en el $i$-esimo individuo (digestibilidad de la MS, FDN y PC de cada forraje) que recibió el $j$-esimo procedimiento (técnica de digestibilidad); $\mu=$ es el promedio general, $\alpha i=$ el efecto

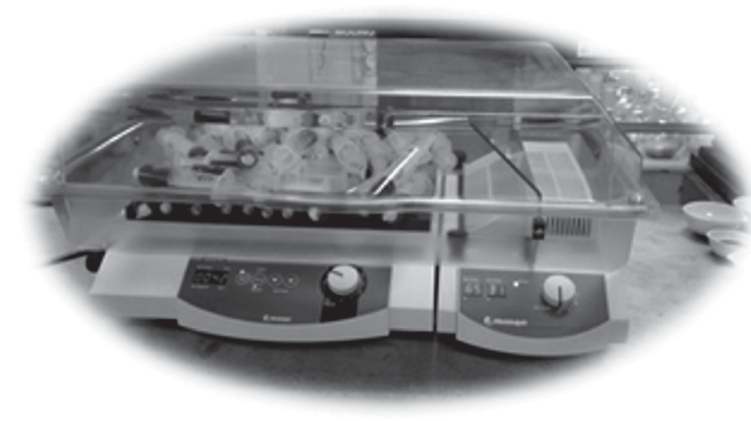

Figura 2. Incubadora con muestras en jeringas (Digestibilidad in vitro)

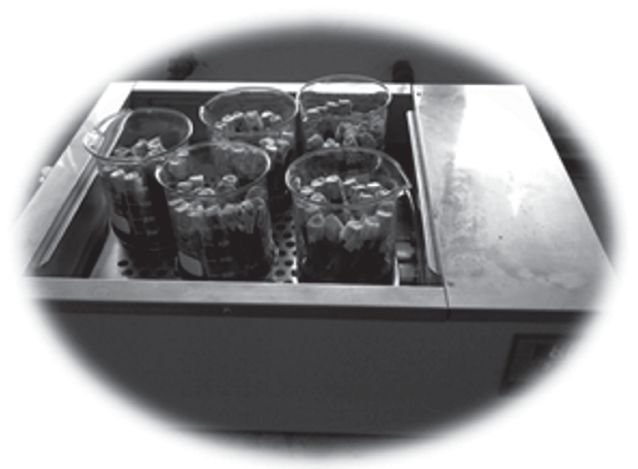

Figura 4. Incubadora con muestras e inoculo pepsinacelulasa

(Digestibilidad enzimática)

del tiempo, $\beta j=$ el efecto del procedimiento o tipo técnica de digestibilidad, y $\varepsilon i j=$ es la cantidad de variación no explicada por el factor, también conocida como Error del Experimento o Variación Residual.

Luego de obtener las digestibilidades de MS, FDN y PC de cada forraje se realizó test de Mauchly para verificar la esfericidad de los datos (homogeneidad) y un análisis de varianza para determinar los rangos de desviación entre las cuatro técnicas y así establecer la tendencia de los datos; las variables evaluadas fueron las digestibilidades de la MS, FDN y PC de los tres forrajes de las cuatro técnicas (tres in vitro y una in situ): luego de verificar las diferencias entre las varianzas, se realizó la comparación de medias mediante test de Bonferroni, haciendo la comparación entre los cuatro procedimientos.

\section{Resultados}

\section{Pennisetum purpureum}

Los promedios de digestibilidad y curvas de degradación de la materia seca (MS), fibra detergente neutro 
(FDN) y proteína cruda (PC) del forraje king grass estimada por los cuatro procedimientos se muestran en la Tabla 2 y Figuras 5, 6 y 7 respectivamente. El test de Mauchly indica que el supuesto de esfericidad (homogeneidad) se cumplió para el efecto del factor procedimiento $(\mathrm{P}>0.05)$ pero no para tiempo, en la digestibilidad de este forraje $\left(\chi^{2}(14)=32.098, P<0.05\right)$, por lo tanto para este efecto los grados de libertad se han corregido con la estimación de Greenhouse Geisser $(\varepsilon=0.294)$. Las pruebas de efectos intra-sujetos muestran que existe una interacción significativa entre los factores: tiempo $(0,6,12,24,48$ y 72 horas) y procedimiento in situ (IS), in vitro inóculo líquido ruminal (IV), in vitro producción de gas (PG) e in vitro enzimática $(E Z)\left(F(15,90)=51.631, P<0.05, \eta^{2}=\right.$ $0.896)$; así mismo existe un efecto principal del tiempo $\left(F(5,30)=3873.51, P<0,05, \eta^{2}=0.998\right)$ en la digestibilidad del forraje; e igualmente existe un efecto principal del procedimiento empleado para su estimación $(\mathrm{F}(3$, $\left.18)=135.691, \mathrm{P}<0.05, \mathrm{n}^{2}=0.958\right)$; algo semejante ocurre con las pruebas inter-sujetos mostrando un efecto significativo en el factor nutriente MS, FDN y PC (F $(2)=$ 69.495, $\left.\mathrm{P}<0.05, \mathrm{\eta}^{2}=0.959\right)$.

Las comparaciones múltiples indican que existen diferencias estadísticamente significativas $(P<0.05)$ en la digestibilidad de la MS a las 12 horas de incubación siendo menor en la técnica in vitro producción de gas (PG) (17.08 \pm 1.03$)$ en comparación con in situ (IS), e in vitro enzimática (EZ) (18.94 \pm 0.56 y $18.76 \pm 0.71$ respectivamente); a las 24 horas fue menor en in vitro inoculación líquido ruminal (IV) y PG $(28.91 \pm 0.91$ y $27.16 \pm 1.37$ respectivamente) seguido por EZ (29.82 $\pm 0.26)$ y ésta a su vez menor que IS (30.10 \pm 0.49$)$; a las 48 horas IV $(38.97 \pm 0.73)$ y PG $(36.60 \pm 1.58)$ fueron menores en comparación con las técnicas IS $(40.57 \pm 3.63)$ y EZ $(40.19 \pm 1.09)$; a las 72 horas continuó la tendencia siendo menor en IV (42.46 \pm 0.92) y PG (39.89 \pm 0.52$)$ en comparación con las otras técnicas IS (44.22 \pm 2.09$)$ y EZ (43.80 \pm 1.44$)$; para todas las demás comparaciones no hubo diferencias estadísticamente significativas $(P>0.05)$ entre las técnicas estudiadas en este forraje (Tabla 2, Figura 5).

En la digestibilidad de la FDN, las comparaciones múltiples también muestran que existen diferencias estadísticamente significativas $(P<0,05)$ a las 6 horas de incubación, siendo con la técnica EZ (13.12 \pm 1.16$)$ menor que las otras tres IS, PG e IV (15.56 \pm 2.25, $15.10 \pm 0.71$ y $14.65 \pm 0.50$ respectivamente); a las 12 horas EZ (23.20 \pm 0.64$)$ fue menor en comparación con las técnicas IV $(25.90 \pm 0.74)$ y PG $(26.69 \pm 0.93)$, y estas a su vez menores que IS (27.52 \pm 0.82$)$; a las 24 horas continuó la tendencia siendo menor en EZ

Tabla 2. Digestibilidad (\%) de materia seca, fibra detergente neutro y proteína cruda en Pennisetum purpureum estimada mediante cuatro técnicas diferentes: in situ (IS) e in vitro: inóculo liquido ruminal (IV), producción de gas (PG) y enzimática (EZ)

\begin{tabular}{|c|c|c|c|c|c|c|c|c|c|c|c|c|}
\hline \multirow{2}{*}{$\begin{array}{l}\text { Tiempo } \\
\text { (Horas) }\end{array}$} & \multicolumn{4}{|c|}{ Materia Seca } & \multicolumn{4}{|c|}{ Fibra Detergente Neutro } & \multicolumn{4}{|c|}{ Proteína Cruda } \\
\hline & IS & IV & PG & EZ & IS & IV & PG & EZ & IS & IV & PG & EZ \\
\hline 6 & $\begin{array}{c}10.71 \\
\pm 1.22^{\mathrm{a}}\end{array}$ & $\begin{array}{c}10.29 \pm \\
0.63^{\mathrm{a}}\end{array}$ & $\begin{array}{c}9.66 \pm \\
0.79^{\mathrm{a}}\end{array}$ & $\begin{array}{c}10.61 \\
\pm 1.59^{a}\end{array}$ & $\begin{array}{c}15.56 \\
\pm 2.25^{b}\end{array}$ & $\begin{array}{c}14.65 \\
\pm 0.50^{b}\end{array}$ & $\begin{array}{c}15.10 \\
\pm 0.71^{b}\end{array}$ & $\begin{array}{r}13.12 \\
\pm 1.16^{\mathrm{a}}\end{array}$ & $\begin{array}{c}13.82 \\
\pm 1.26^{b}\end{array}$ & $\begin{array}{c}13.10 \pm \\
2.16^{b}\end{array}$ & $\begin{array}{c}13.04 \\
\pm 0.57^{b}\end{array}$ & $\begin{array}{c}11.52 \\
\pm \\
2.02^{\mathrm{a}}\end{array}$ \\
\hline 12 & $\begin{array}{c}18.94 \\
\pm 0.56^{b}\end{array}$ & $\begin{array}{c}18.18 \pm \\
0.98^{a b}\end{array}$ & $\begin{array}{c}17.08 \\
\pm 1.03^{\mathrm{a}}\end{array}$ & $\begin{array}{c}18.76 \\
\pm 0.71^{b}\end{array}$ & $\begin{array}{c}27.52 \\
\pm 0.82^{\mathrm{C}}\end{array}$ & $\begin{array}{c}25.90 \\
\pm 0.74^{b}\end{array}$ & $\begin{array}{c}26.69 \\
\pm 0.93^{b}\end{array}$ & $\begin{array}{c}23.20 \\
\pm 0.64^{\mathrm{a}}\end{array}$ & $\begin{array}{c}24.43 \\
\pm 0.90^{c}\end{array}$ & $\begin{array}{c}23.16 \pm \\
1.83^{b}\end{array}$ & $\begin{array}{c}23.06 \\
\pm 0.75^{b}\end{array}$ & $\begin{array}{c}20.36 \\
\pm \\
0.29^{a}\end{array}$ \\
\hline 24 & $\begin{array}{c}30.10 \\
\pm 0.49^{c}\end{array}$ & $\begin{array}{c}28.91^{ \pm} \\
0.91^{\mathrm{a}}\end{array}$ & $\begin{array}{r}27.16 \\
\pm 1.37^{\mathrm{a}}\end{array}$ & $\begin{array}{c}29.82 \\
\pm 0.26^{b}\end{array}$ & $\begin{array}{c}43.75 \\
\pm 0.60^{\mathrm{c}}\end{array}$ & $\begin{array}{c}41.17 \\
\pm 0.66^{b}\end{array}$ & $\begin{array}{c}42.43 \\
\pm 1.24^{b}\end{array}$ & $\begin{array}{c}36,89 \\
\pm 1.20^{\mathrm{a}}\end{array}$ & $\begin{array}{c}38.84 \\
\pm 0.58^{\mathrm{C}}\end{array}$ & $\begin{array}{c}36.81 \pm \\
0.70^{b}\end{array}$ & $\begin{array}{c}36.66 \\
\pm 0.99^{b}\end{array}$ & $\begin{array}{c}32.37 \\
\pm \\
0.28^{a}\end{array}$ \\
\hline 48 & $\begin{array}{c}40.57 \\
\pm 3.63^{b}\end{array}$ & $\begin{array}{c}38.97 \pm \\
0.73^{\mathrm{a}}\end{array}$ & $\begin{array}{r}36.60 \\
\pm 1.58^{\mathrm{a}}\end{array}$ & $\begin{array}{c}40.19 \\
\pm 1.09^{b}\end{array}$ & $\begin{array}{c}58.96 \\
\pm 1.41^{b}\end{array}$ & $\begin{array}{c}55.49 \\
\pm 0.51^{b}\end{array}$ & $\begin{array}{c}57.19 \\
\pm 1.43^{b}\end{array}$ & $\begin{array}{c}49.72 \\
\pm 2.72^{\mathrm{a}}\end{array}$ & $\begin{array}{c}52.35 \\
\pm 1.66^{b}\end{array}$ & $\begin{array}{c}49.62 \pm \\
1.30^{\mathrm{ab}}\end{array}$ & $\begin{array}{r}49.42 \\
\pm 1.14^{\mathrm{a}}\end{array}$ & $\begin{array}{c}43.62 \\
\pm \\
1.19^{\mathrm{a}}\end{array}$ \\
\hline 72 & $\begin{array}{c}44.22 \\
\pm 2.09^{b}\end{array}$ & $\begin{array}{c}42.46 \pm \\
0.92^{\mathrm{a}}\end{array}$ & $\begin{array}{c}39.89 \\
\pm 0.52^{\mathrm{a}}\end{array}$ & $\begin{array}{c}43.80 \\
\pm 1.44^{b}\end{array}$ & $\begin{array}{c}64.26 \\
\pm 1.37^{b}\end{array}$ & $\begin{array}{c}60.47 \\
\pm 0.68^{b}\end{array}$ & $\begin{array}{c}62.32 \\
\pm 0.47^{b}\end{array}$ & $\begin{array}{c}54.18 \\
\pm 0.37^{a}\end{array}$ & $\begin{array}{r}57.05 \\
\pm 0.57^{b}\end{array}$ & $\begin{array}{c}54.07 \pm \\
2.48^{\mathrm{b}}\end{array}$ & $\begin{array}{r}53.85 \\
\pm 0.37^{b}\end{array}$ & $\begin{array}{c}47.54 \\
\pm \\
1.40^{\mathrm{a}}\end{array}$ \\
\hline
\end{tabular}

Valores expresados como promedio \pm error estándar de la media.

Letras diferentes en la misma fila indican diferencias estadísticamente significativas $(P<0.05)$. 


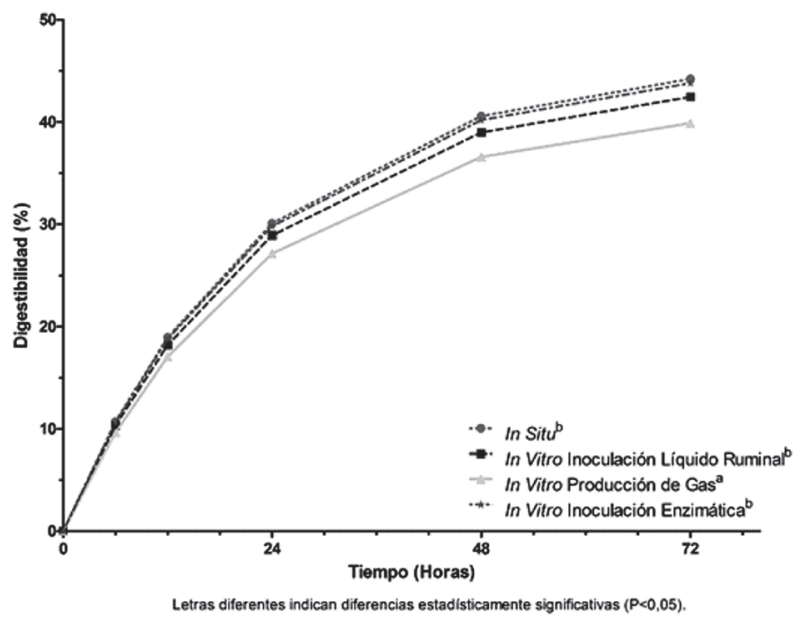

Figura 5. Digestibilidad (\%) de la materia seca en Pennisetum purpureum estimada mediante cuatro procedimientos diferentes: in situ e in vitro: inoculación líquido numinal, producción de gas y enzimático.

(36.89 \pm 1.20$)$ en comparación con IV $(41.17 \pm 0.66)$ y PG (42.43 \pm 1.24$)$, que a su vez fueron menores que IS (43.75 \pm 0.60$) ;$ a las 48 horas EZ (49.72 \pm 2.72$)$ fue menor que las otras tres IS, PG e IV $(58.96 \pm 1.41,57.19 \pm$ 1.43 y $55.49 \pm 0.51$ respectivamente); a las 72 horas se mantuvo la tendencia siendo menor en EZ $(54.18 \pm 0.37)$ en comparación con las otras tres IS, PG e IV (64.26 \pm $1.37,62.32 \pm 0.47$ y $60.47 \pm 0.68$ respectivamente); para todas las demás comparaciones no hubo diferencias estadísticamente significativas $(P>0.05)$ entre las técnicas estudiadas en este forraje (Tabla 2, Figura 6).

En el tercer nutriente estudiado, las comparaciones múltiples de la digestibilidad de la PC revelan que existen diferencias estadísticamente significativas $(P<0.05)$ a las 6 horas de incubación, siendo nuevamente con la técnica EZ (11.52 \pm 2.02$)$, menor que IS, IV y PG (13.82 $\pm 1.26,13.10 \pm 2.16$ y PG (13.04 \pm 0.57$) ;$ a las 12 horas EZ $(20.36 \pm 0.29)$ fue menor que IV y PG $(23.16 \pm$ 1.83 y $23.06 \pm 0.75)$ y estás a su vez menores que IS $(24.43 \pm 0.90) ;$ a las 24 horas continuó la tendencia IS $(38.84 \pm 0.58)$ fue mayor que IV (36.81 \pm 0.70$)$ y PG (36.66 \pm 0.99$)$, y estás a su vez mayores que EZ (32.37 $\pm 0.28)$; a las 48 horas IS $(52.35 \pm 1.66)$ fue mayor a la estimación obtenida mediante las técnicas PG y EZ (49.42 \pm 1.14 y $43.62 \pm 1.19$ respectivamente); $y$ a las 72 horas EZ $(47.54 \pm 1.40)$ fue menor a la estimación obtenida mediante la técnica IS, IV y PG (57.05 \pm 0.57 , $54.07 \pm 2.48$ y $53.85 \pm 0.37$ respectivamente), para todas las demás comparaciones no hubo diferencias estadísticas ( $P>0.05)$ entre las técnicas estudiadas en este forraje (Tabla 2, Figura 7).

La cinética de degradación de la MS fue similar $(P>0.05)$ en las tres técnicas IS, IV y PG, pero fueron

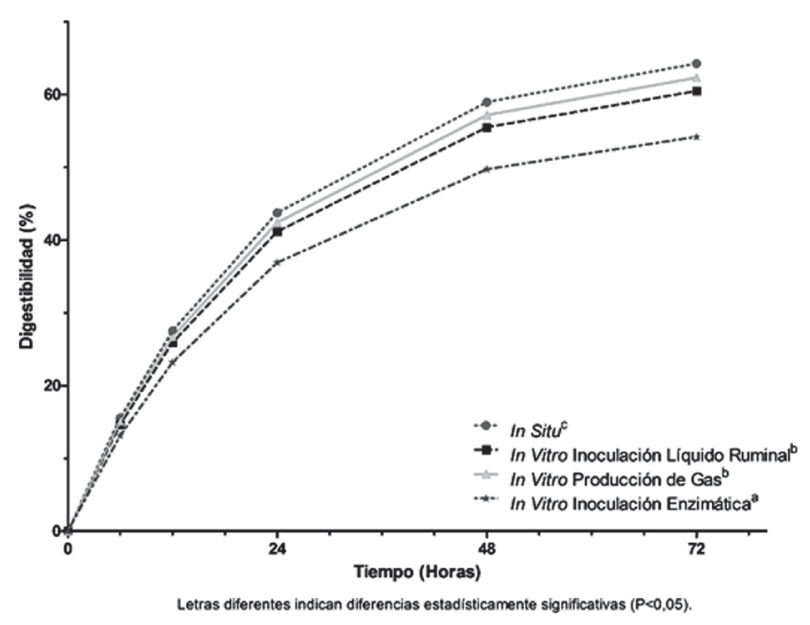

Figura 6. Digestibilidad (\%) de la fibra detergente neutro en Pennisetum purpureum estimada mediante cuatro procedimientos diferentes: in situ e in vitro: inoculación líquido numinal, producción de gas y enzimático.

mayores $(\mathrm{P}<0.05)$ que $E Z$; mientras que en la $F D N$ se observó un mayor valor en la estimación IS, en comparación con IV y PG, y éstas a su vez mayores que EZ $(\mathrm{P}<0.05)$; por otro lado, en la PC se observó un mayor valor en la estimación IS en comparación con IV, y ésta a su vez mayor que EZ $(\mathrm{P}<0.05)$, mientras que PG resulto se similar a las dos primeras $(\mathrm{P}>0.05)$ (Figuras $5,6$ y 7$)$.

La digestibilidad tanto de la MS como FDN y PC estimadas mediante las técnicas IV, PG y EZ, están altamente correlacionadas positivamente $(\mathrm{P}<0.05)$, con la digestibilidad IS, encontrando que para la primera sus valores son: (MS) $r=0.9844,($ FDN) $r=$

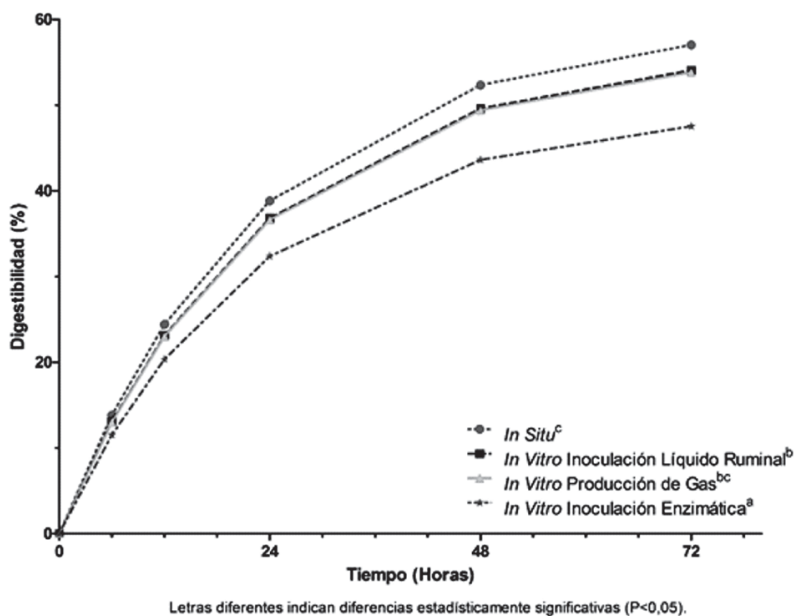

Figura 7. Digestibilidad (\%) de la proteína cruda en Pennisetum purpureum estimada mediante cuatro procedimientos diferentes: in situ e in vitro: inoculación líquido numinal, producción de gas y enzimático. 
Tabla 3. Regresiones lineales entre digestibilidad de la materia seca in situ (DISMS) y digestibilidad de la materia seca in vitro: inóculo liquido ruminal (DIVMS), producción de gas (DPGMS) y enzimática (DEZMS) en Pennisetum purpureum

\begin{tabular}{|l|}
\hline DISMS $=-0.5504+1.079$ DIVMS \\
\hline DISMS $=0.3823+1.049$ DPGMS \\
\hline DISMS $=0.2307+0.8585$ DEZMS \\
\hline
\end{tabular}

0.9952 y $(\mathrm{PC}) \mathrm{r}=0.9896$; para la segunda $(\mathrm{MS}) \mathrm{r}=$ 0.9820, (FDN) $r=0.9739$ y (PC) $r=0.9765$, y para la tercera (MS) $r=0.9827,(F D N) r=0.9379$ y (PC) $r=0.9257$; así mismo, el análisis de regresión lineal muestra la existencia de una relación entre las variables digestibilidad de la MS estimada mediante la técnica IS con respecto a la estimación IV, PG y EZ, que es explicada por las ecuaciones de la Tabla 3, en la que es la digestibilidad (\%) de la materia seca estimada mediante la técnica in situ, en la primera ecuación es la estimación in vitro incubación con líquido ruminal; para el segundo caso es la estimación in vitro producción de gas, y para el tercero es la estimación in vitro enzimática (Figura 8); por lo tanto las variables digestibilidad IS de la MS, FDN y PC se explican en un $96.9\left(r^{2}=0.9690\right), 99\left(r^{2}\right.$ $=0.9903), 97.9 \%\left(r^{2}=0.9794\right) ; 96.4\left(r^{2}=0.9643\right)$, $94.9\left(r^{2}=0.9485\right), 95.4 \%\left(r^{2}=0.9536\right)$, y $96.6\left(r^{2}\right.$ $=0.9657), 67.6\left(r^{2}=0.6758\right)$ y $85.7 \%\left(r^{2}=0.8569\right)$ por la digestibilidad IV, PG y EZ respectivamente.

\section{Hibiscus rosa-sinensis}

Los promedios de digestibilidad y curvas de degradación de la materia seca (MS), fibra detergente neutro (FDN) y proteína cruda (PC) del forraje cayeno en los cuatro procedimientos se muestran en la Tabla 4 y Figuras 9, 10 y 11 respectivamente. El test de Mauchly indica que el supuesto de esfericidad (homogeneidad) no se cumplió para los efectos de los factores tiempo ni procedimiento en la digestibilidad de este forraje $\left(\chi^{2}(14)=47.687, P<0.05 ; y \quad \chi^{2}(5)=16.449, P<0.05\right.$ respectivamente), por lo tanto para estos efectos los
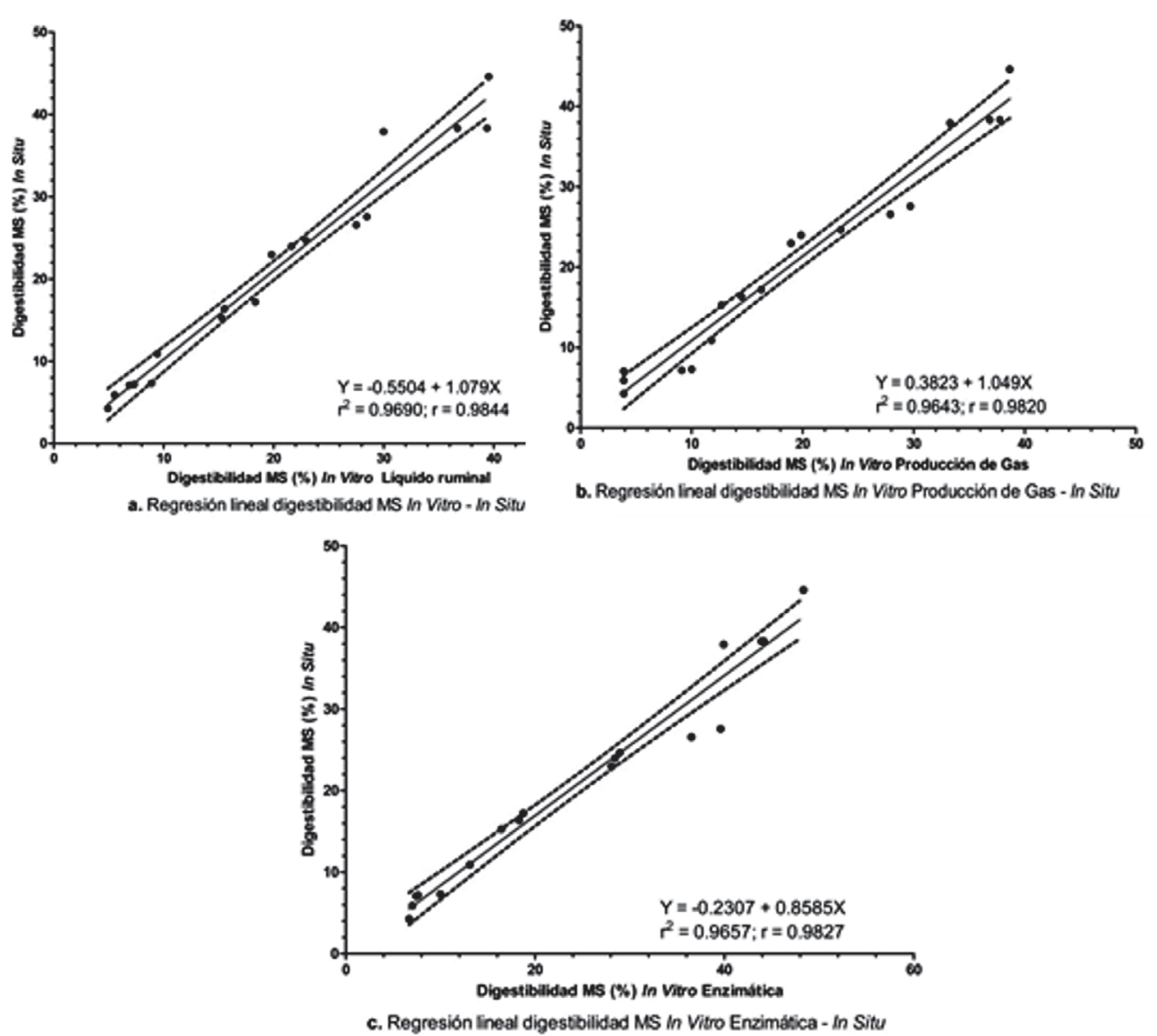

Figura 8. Regresiones lineales entre digestibilidad de la materia seca in situ y digestibilidad de la materia seca in vitro: inóculo líquido ruminal (a), producción de gas (b) y enzimática (c) en Pennisetum purpureum 
grados de libertad se han corregido con la estimación de Greenhouse Geisser $(\varepsilon=0.231$ y 0.447 respectivamente). Las pruebas de efectos intra-sujetos muestran que existe una interacción significativa entre los factores: tiempo $(0,6,12,24,48$ y 72 horas) y técnica de digestibilidad in situ (IS), in vitro inóculo líquido ruminal (IV), in vitro producción de gas (PG) e in vitro enzimática $(E Z)\left(F(15,90)=13.361, P<0.05, \eta^{2}=0.69\right)$; así mismo existe un efecto principal del tiempo ( $\mathrm{F}(5$, $\left.30)=1754.625, \mathrm{P}<0.05, \mathrm{\eta}^{2}=0.997\right)$ en la digestibilidad del forraje; e igualmente existe un efecto principal de la técnica empleada para su estimación $(\mathrm{F}(3$, $\left.18)=12.081, \mathrm{P}<0.05, \mathrm{n}^{2}=0.668\right)$; algo semejante ocurre con las pruebas inter-sujetos mostrando un efecto significativo en el factor nutriente MS, FDN y PC $(F(2)=$ 24.697, $\left.\mathrm{P}<0.05, \mathrm{\eta}^{2}=0.892\right)$.

Las comparaciones múltiples indican que existen diferencias estadísticamente significativas $(P<0.05)$ en la digestibilidad de la MS a las 6 horas de incubación, siendo menor en la técnica in vitro inoculación con líquido ruminal (IV) (19.20 \pm 1.75$)$ en comparación con las otras tres: in situ (IS) e in vitro enzimática (EZ) y producción de gas (PG) $(20.33 \pm 0.45 ; 20.35 \pm 1.61$ y $20.39 \pm 1.58$ respectivamente); a las 12 horas fue menor en IV (33.95 \pm 1.70$)$, en comparación con las otras tres EZ, PG e IS $(36.05 \pm 0.42,35.98 \pm 2.04$ y $35.95 \pm$ 0.91 respectivamente); a las 24 horas IV (53.98 \pm 1.23$)$ fue la menor de las cuatro técnicas, siendo mayores en EZ (57.31 \pm 1.17$)$ y PG (57.19 \pm 0.77$)$; a las 48 fue menor en la técnica IV $(72.76 \pm 1.69)$ y PG (77.09 \pm 6.96), siendo mayor en EZ (77.25 \pm 0.35$)$; para todas las demás comparaciones no hubo diferencias estadís-

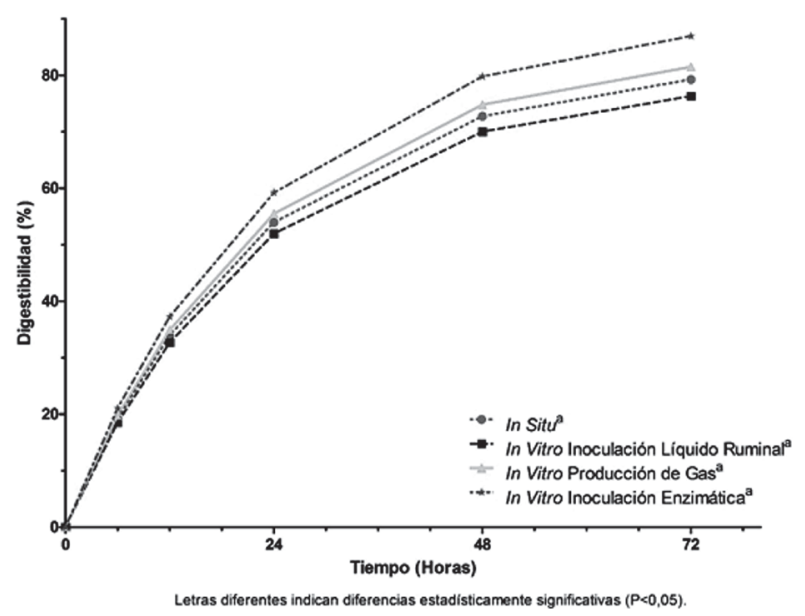

Figura 10. Digestibilidad (\%) de la fibra detergente en Hibiscus rosa-sinensis estimada mediante cuatro procedimientos diferentes: in situ e in vitro: inoculación líquido numinal, producción de gas y enzimático.

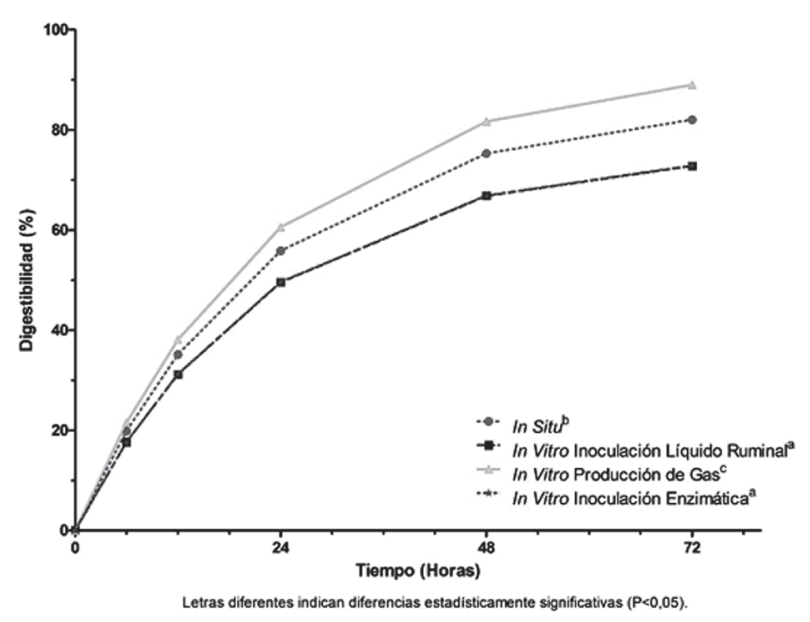

Figura 11. Digestibilidad (\%) de la proteína bruta en Hibiscus rosa-sinensis estimada mediante cuatro procedimientos diferentes: in situ e in vitro: inoculación líquido numinal, producción de gas y enzimático.

ticamente significativas $(P>0.05)$ entre las técnicas estudiadas en este forraje (Tabla 4, Figura 9).

En la digestibilidad de la FDN las comparaciones múltiples muestran que existen diferencias estadísticamente significativas $(\mathrm{P}<0.05)$ a las 6 horas de incubación, se observó que la técnica IV $(18.48 \pm 1.25)$ fue menor que EZ (21.06 \pm 1.24$)$; a las 12 horas EZ y PG (37.24 \pm 0.31 y $34.90 \pm 2.27$ respectivamente) fueron mayores a IS (33.94 \pm 0.46$)$, y esta a su vez mayor que IV (32.67 $\pm 1.15)$; a las 24 horas EZ (59.20 \pm 0.88$)$ fue la mayor de todas, seguida por PG (55.49 \pm 0.86$)$, y esta a su vez mayor que e IV (51.94 \pm 0.69$)$; a las 72 horas EZ $(86.95 \pm 0.20)$ fue mayor que las técnicas IS (79.26 \pm $0.61)$ e IV (76.30 \pm 0.97$)$; para todas las demás comparaciones no hubo diferencias estadísticamente significativas $(P>0.05)$ entre las técnicas estudiadas en este forraje (Tabla 4, Figura 10).

En el tercer nutriente estudiado, las comparaciones múltiples de la digestibilidad de la PC revelan que existen diferencias estadísticamente significativas $(P<0.05)$ a las 6 horas de incubación, indicando que con las técnicas IV (17.64 \pm 1.55$)$ y EZ (17.66 \pm 0.29$)$, fueron menores que con IS $(19.88 \pm 1.23)$, y esta a su vez menor que PG $(21.56 \pm 1.67)$; a las 12 horas fue menor IV (31.18 \pm 1.46$)$ y EZ (31.22 \pm 0.56$)$, y éstas a su vez menores que PG $(38.13 \pm 2.13)$; y a las 24 horas PG $(60.61 \pm 0.80)$ fue mayor que IV $(49.57 \pm 1.20)$ y EZ (49.64 \pm 1.52$)$; para todas las demás comparaciones no hubo diferencias estadísticamente significativas $(P>0.05)$ entre las técnicas estudiadas en este forraje (Tabla 4, Figura 11). 


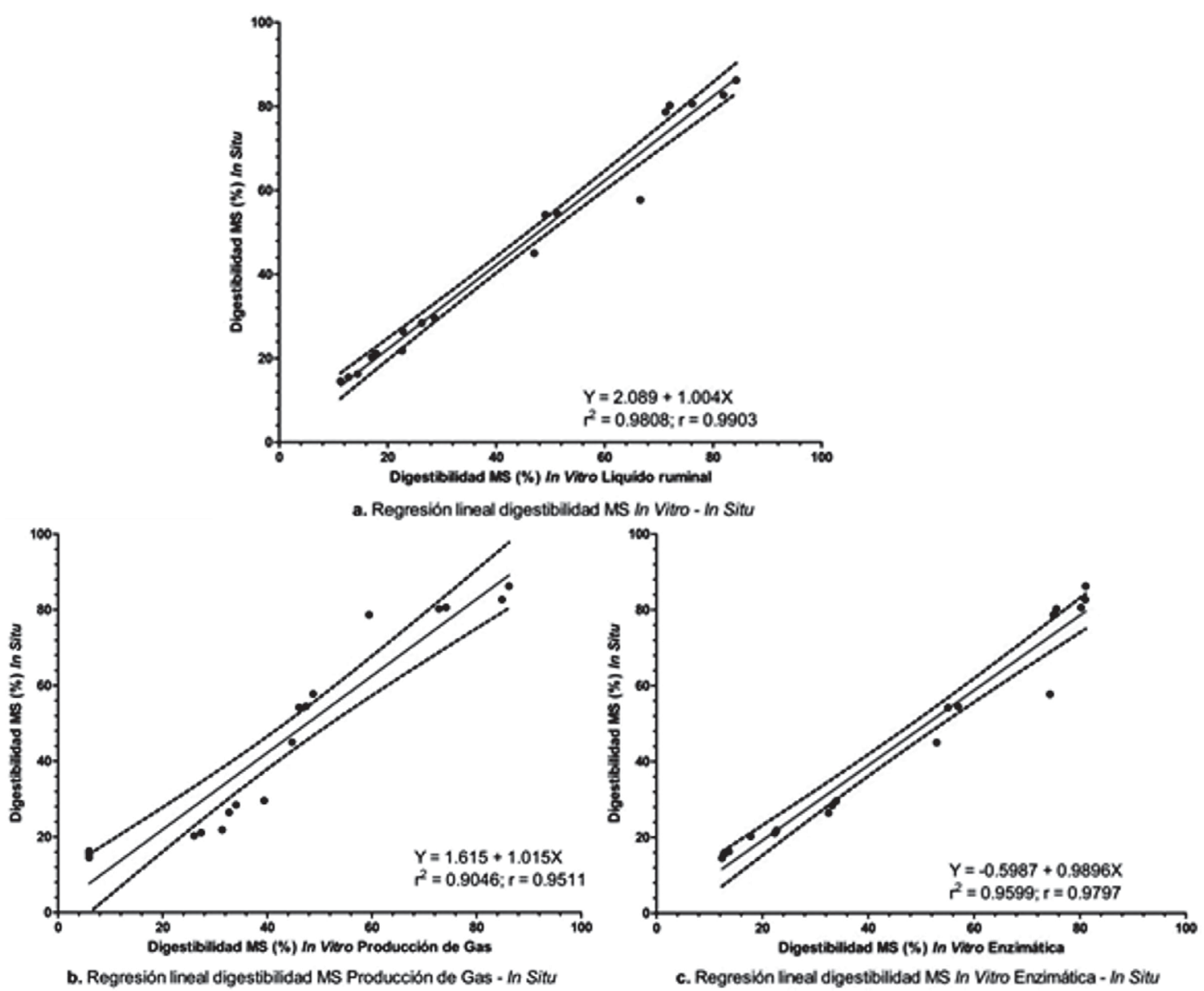

Figura 12. Regresiones lineales entre digestibilidad de la materia seca in situ y digestibilidad de la materia seca in vitro: inóculo líquido ruminal (a), producción de gas (b) y enzimática (c) en Hibiscus rosa-sinensis

Tabla 5. Regresiones lineales entre digestibilidad de la materia seca in situ (DISMS) y digestibilidad de la materia seca in vitro: inoculación liquido ruminal (DIVMS), producción de gas (DPGMS) y enzimática (DEZMS) en Hibiscus rosa-sinensis

\begin{tabular}{|c|}
\hline DISMS $=2.089+1.004$ DIVMS \\
\hline DISMS $=1.615+1.015$ DPGMS \\
\hline DISMS $=-0.5987+0.9896$ DEZMS \\
\hline
\end{tabular}

La cinética de degradación de la MS fue mayor en la técnica IV, en comparación con $E Z(P<0.05)$, y ésta dos últimas similares a IS y PG $(P>0.05)$; mientras que en la FDN no se observaron diferencias entre las cuatro técnicas ( $\mathrm{P}>0.05)$; por otro lado, en la PC se observó una menor digestibilidad en las estimaciones EZ e IV en comparación con IS, y ésta a su vez menor que PG $(\mathrm{P}<0.05)$ (Figuras 9, 10 y 11 ).
La digestibilidad tanto de la MS como FDN y PC estimadas mediante las técnicas IV, PG y EZ, están altamente correlacionadas positivamente con la digestibilidad IS $(\mathrm{P}<0.05)$, encontrando que para la primera sus valores son: $(\mathrm{MS}) \mathrm{r}=0.9903,(\mathrm{FDN}) \mathrm{r}=0.9937$ y (PC) $r=0.9911$; para la segunda (MS) $r=0.9511$, $(\mathrm{FDN}) r=0.9798$ y $(\mathrm{PC}) r=0.9832$, y para la tercera (MS) $r=0.9797,(F D N) r=0.9557$ y (PC) $r=0.9560$ (Figura 12).

Así mismo, el análisis de regresión lineal muestra la existencia de una relación entre las variables digestibilidad de la MS estimada mediante la técnica IS con respecto a la estimación IV, PG y EZ, que es explicada por las ecuaciones de la Tabla 5, en la cual la es la digestibilidad (\%) de la materia seca estimada mediante la técnica in situ, en la primera ecuación es la estimación in vitro incubación con líquido ruminal; para el segundo caso es la estimación in vitro producción de gas, y para el ter- 
Tabla 6. Digestibilidad (\%) de materia seca, fibra detergente neutro y proteína cruda en Gliricidia sepium estimada mediante cuatro técnicas diferentes: in situ (IS) e in vitro: inóculo liquido ruminal (IV), producción de gas (PG) y enzimática (EZ)

\begin{tabular}{|c|c|c|c|c|c|c|c|c|c|c|c|c|}
\hline \multirow{2}{*}{$\begin{array}{l}\text { Tiempo } \\
\text { (Horas) }\end{array}$} & \multicolumn{4}{|c|}{ Materia Seca } & \multicolumn{4}{|c|}{ Fibra Detergente Neutro } & \multicolumn{4}{|c|}{ Proteína Cruda } \\
\hline & IS & IV & PG & EZ & IS & IV & PG & EZ & IS & IV & PG & EZ \\
\hline 6 & $\begin{array}{c}15.05 \\
\pm 1.08^{b}\end{array}$ & $\begin{array}{c}14.01 \\
\pm 0.94^{b}\end{array}$ & $\begin{array}{c}14.11 \\
\pm 0.45^{b}\end{array}$ & $\begin{array}{c}7.88 \pm \\
0.97^{\mathrm{a}}\end{array}$ & $\begin{array}{c}18.53 \\
\pm 2.34^{\mathrm{c}}\end{array}$ & $\begin{array}{c}17.78 \\
\pm 0.52^{b}\end{array}$ & $\begin{array}{c}18.05 \pm \\
0.19^{b c}\end{array}$ & $\begin{array}{c}16.74 \\
\pm 0.92^{\mathrm{a}}\end{array}$ & $\begin{array}{c}16.12 \\
\pm 3.96^{\mathrm{C}}\end{array}$ & $\begin{array}{c}13.93 \pm \\
0.87^{b}\end{array}$ & $\begin{array}{c}14.39 \pm \\
0.37^{\text {bc }}\end{array}$ & $\begin{array}{c}10.17 \\
\pm 0.98^{\mathrm{a}}\end{array}$ \\
\hline 12 & $\begin{array}{c}26.61 \\
\pm 2.70^{\mathrm{C}}\end{array}$ & $\begin{array}{c}24.77 \\
\pm 0.93^{b}\end{array}$ & $\begin{array}{c}24.95 \\
\pm 1.07^{b}\end{array}$ & $\begin{array}{c}13.93 \\
\pm 0.79^{\mathrm{a}}\end{array}$ & $\begin{array}{c}32.77 \\
\pm 1.18^{\mathrm{c}}\end{array}$ & $\begin{array}{c}31.44 \\
\pm 0.49^{b}\end{array}$ & $\begin{array}{c}31.91 \pm \\
0.46^{b c}\end{array}$ & $\begin{array}{c}29.60 \\
\pm 0.74^{\mathrm{a}}\end{array}$ & $\begin{array}{c}28.49 \\
\pm 0.36^{\mathrm{C}}\end{array}$ & $\begin{array}{c}24.63 \pm \\
0.82^{b}\end{array}$ & $\begin{array}{r}25.45 \\
\pm 0.88^{\mathrm{c}}\end{array}$ & $\begin{array}{r}17.99 \\
\pm 0.54^{\mathrm{a}}\end{array}$ \\
\hline 24 & $\begin{array}{c}42.31 \\
\pm 1.98^{\mathrm{C}}\end{array}$ & $\begin{array}{c}39.38 \\
\pm 1.18^{b}\end{array}$ & $\begin{array}{c}39.66 \\
\pm 1.85^{b}\end{array}$ & $\begin{array}{c}22.14 \\
\pm 1.06^{\mathrm{a}}\end{array}$ & $\begin{array}{c}52.09 \\
\pm \\
0.05^{d}\end{array}$ & $\begin{array}{c}49.99 \\
\pm 0.44^{b}\end{array}$ & $\begin{array}{c}50.74 \pm \\
0.79^{\mathrm{c}}\end{array}$ & $\begin{array}{r}47.06 \\
\pm 0.99^{\mathrm{a}}\end{array}$ & $\begin{array}{c}45.30 \\
\pm 1.58^{d}\end{array}$ & $\begin{array}{c}39.16 \pm \\
1.09^{b}\end{array}$ & $\begin{array}{r}40.45 \\
\pm 1.52^{\mathrm{C}}\end{array}$ & $\begin{array}{c}28.60 \\
\pm 1.30^{\mathrm{a}}\end{array}$ \\
\hline 48 & $\begin{array}{c}57.02 \\
\pm 0.86^{\mathrm{C}}\end{array}$ & $\begin{array}{c}53.07 \\
\pm 0.76^{b}\end{array}$ & $\begin{array}{c}53.46 \\
\pm 2.41^{b}\end{array}$ & $\begin{array}{c}29.84 \\
\pm 0.20^{a}\end{array}$ & $\begin{array}{c}70.21 \\
\pm 0.59^{\mathrm{c}}\end{array}$ & $\begin{array}{c}67.38 \\
\pm 0.24^{b}\end{array}$ & $\begin{array}{c}68.39 \pm \\
1.03^{b c}\end{array}$ & $\begin{array}{c}63.43 \\
\pm 0.18^{\mathrm{a}}\end{array}$ & $\begin{array}{c}61.06 \\
\pm 1.64^{\mathrm{C}}\end{array}$ & $\begin{array}{c}52.78 \pm \\
0.71^{b}\end{array}$ & $\begin{array}{c}54.52 \pm \\
1.99^{b c}\end{array}$ & $\begin{array}{c}38.54 \\
\pm 0.24^{\mathrm{a}}\end{array}$ \\
\hline 72 & $\begin{array}{c}62.14 \\
\pm 1.39^{c}\end{array}$ & $\begin{array}{c}57.84 \\
\pm 1.23^{b}\end{array}$ & $\begin{array}{c}58.26 \\
\pm 2.41^{b}\end{array}$ & $\begin{array}{r}32.52 \\
\pm 2.21^{\mathrm{a}}\end{array}$ & $\begin{array}{c}76.52 \\
\pm \\
1.12^{b}\end{array}$ & $\begin{array}{c}73.42 \\
\pm \\
0.75^{\mathrm{ab}}\end{array}$ & $\begin{array}{c}74.53 \pm \\
1.03^{a b}\end{array}$ & $\begin{array}{c}69.12 \\
\pm 1.36^{a}\end{array}$ & $\begin{array}{c}66.54 \\
\pm 0.96^{\mathrm{c}}\end{array}$ & $\begin{array}{c}57.51 \pm \\
1.19^{b}\end{array}$ & $\begin{array}{c}59.42 \pm \\
1.99^{b c}\end{array}$ & $\begin{array}{r}42.00 \\
\pm 2.54^{\mathrm{a}}\end{array}$ \\
\hline
\end{tabular}

Valores expresados como promedio \pm error estándar de la media.

Letras diferentes en la misma fila indican diferencias estadísticamente significativas $(\mathrm{P}<0.05)$.

cer caso es la estimación in vitro enzimática (Figura 12); por lo tanto, las variables digestibilidades IS de la MS, FDN y PC se explican en un $98.1\left(r^{2}=0.9808\right), 98.7\left(r^{2}\right.$ $=0.9874), 98.2 \%\left(r^{2}=0.9822\right) ; 90.5\left(r^{2}=0.9046\right), 96\left(r^{2}\right.$ $=0.9600), 96.7 \%\left(r^{2}=0.9666\right) ;$ y $96\left(r^{2}=0.9599\right), 91.3$ $\left(r^{2}=0.9134\right), 91.4 \%\left(r^{2}=0.9140\right)$ por la digestibilidad IV, PG y EZ respectivamente.

\section{Gliricidia sepium}

Los promedios de digestibilidad y curvas de degradación de la materia seca (MS), fibra detergente neutro (FDN) y proteína cruda (PC) del forraje matarratón en los cuatro procedimientos se muestran en la Tabla 6 y Figuras 13, 14 y 15 respectivamente. El test de Mauchly indica que el supuesto de esfericidad se cumplió para el efecto del factor procedimiento $(\mathrm{P}>0.05)$ pero no para el tiempo $\left(\chi^{2}(14)=26.522, P<0.05\right)$, en la digestibilidad de este forraje, por lo tanto para este efecto los grados de libertad se han corregido con la estimación de Greenhouse Geisser $(\varepsilon=0.405)$. Las pruebas de efectos intra-sujetos muestran que existe una interacción significativa entre los factores: tiempo $(0,6,12,24,48$ y 72 horas) y técnica de digestibilidad in situ (IS), in vitro inóculo líquido ruminal (IV), in vitro producción de gas (PG) e in vitro enzimática (EZ) $\left(\mathrm{F}(15,90)=126.723, \mathrm{P}<0.05, \eta^{2}=0.955\right)$; así mismo existe un efecto principal del tiempo $(F(5,30)=$ 3705.205, $\mathrm{P}<0,05, \mathrm{\eta}^{2}=0.998$ ) en la digestibilidad del forraje; e igualmente existe un efecto principal de la técnica empleada para su estimación $(F(3,18)=$

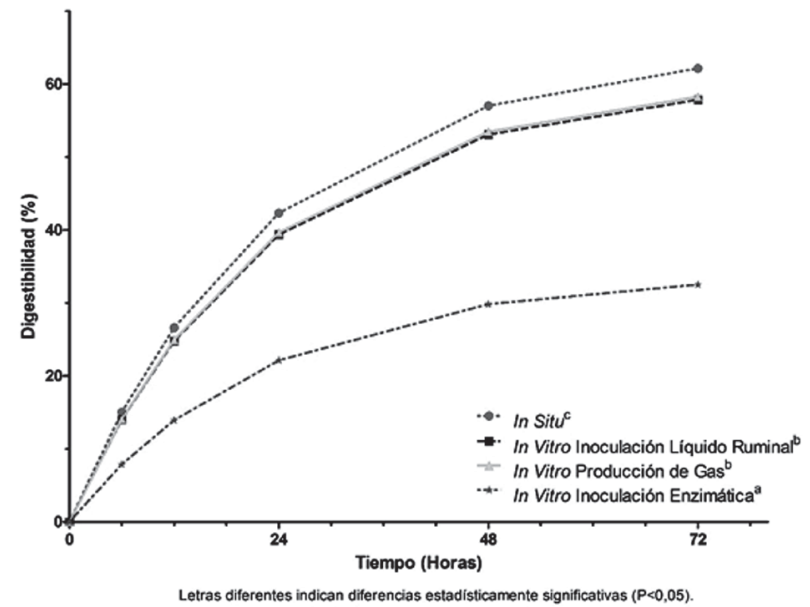

Figura 13. Digestibilidad (\%) de la materia seca en Gliricidia sepium estimada mediante cuatro procedimientos diferentes: in situ e in vitro: inoculación líquido numinal, producción de gas y enzimático.

1334.241, $\left.\mathrm{P}<0.05, \mathrm{\eta}^{2}=0.996\right) ;$ algo semejante ocurre con las pruebas inter-sujetos mostrando un efecto significativo en el factor nutriente MS, FDN y PC $(F(2)=$ 128.555, $\left.\mathrm{P}<0.05, \mathrm{\eta}^{2}=0.977\right)$.

Las comparaciones múltiples indican que existen diferencias estadísticamente significativas $(\mathrm{P}<0.05)$ en la digestibilidad de la MS a las 6 horas de incubación, siendo menor en la técnica in vitro enzimática (EZ) (7.88 \pm 0.97$)$, en comparación con las otras tres: in 


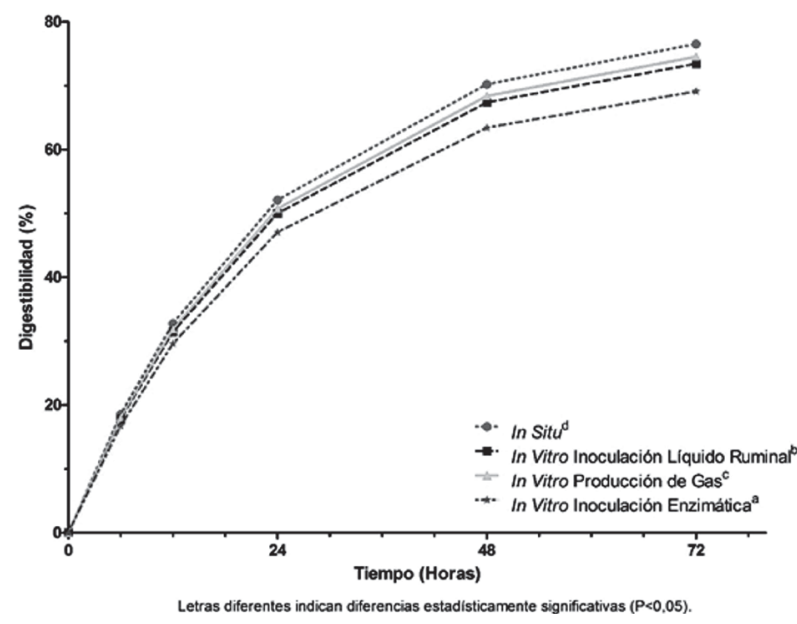

Figura 14. Digestibilidad (\%) de la fibra detergente en Gliricidia sepium estimada mediante cuatro procedimientos diferentes: in situ e in vitro: inoculación líquido numinal, producción de gas y enzimático.

vitro producción de gas (PG) $(14.11 \pm 0.45)$, in vitro inoculación líquido ruminal (IV) (14.01 \pm 0.94$)$ e in situ (IS) (15.05 \pm 1.08$)$; a las 12 horas EZ (13.93 \pm 0.79$)$ fue la menor, seguida por las técnicas IV $(24.77 \pm 0.93)$ y PG $(24.95 \pm 1.07)$, siendo la mayor IS $(26.61 \pm 2.70)$; a las 24 horas EZ (22.14 \pm 1.06$)$ fue la menor, seguida por las técnicas IV $(39.38 \pm 1.18)$ y PG $(39.66 \pm 1.85)$, siendo la mayor IS $(42.31 \pm 1.98)$; a las 48 horas EZ $(29.84 \pm 0.20)$ fue la menor, seguida por las técnicas IV $(53.07 \pm 0.76)$ y PG $(53.46 \pm 2.41)$, siendo la mayor IS (57.02 \pm 0.86$) ; y$ a las 72 horas se mantuvo la tendencia siendo menor en la técnica EZ (32.52 \pm 2.21$)$, seguida por IV $(57.84 \pm 1.23)$ y PG $(58.26 \pm 1.04)$, y siendo la mayor IS (62.14 \pm 1.39$) ;$ para todas las demás comparaciones no hubo diferencias estadísticamente significativas $(P>0.05)$ entre las técnicas estudiadas en este forraje (Tabla 6, Figura 13).

En la digestibilidad de la FDN, las comparaciones múltiples muestran que existen diferencias estadísticamente significativas $(\mathrm{P}<0,05)$ a las 6 horas de incubación, siendo mayor en la técnica IS (18.53 \pm 2.34$)$ en comparación con IV $(17.78 \pm 0.52)$, y esta a su vez mayor que EZ (16.74 \pm 0.92$) ;$ a las 12 horas EZ (29.60 \pm 0.74$)$ fue la menor de todas, seguida por la técnica IV (31.44 $\pm 0.49)$, siendo mayor en IS (32.77 \pm 1.18$)$; a las 24 horas fue menor en la técnica EZ (47.06 \pm 0.99$)$, seguido por IV $(49.99 \pm 0.44)$, y esta a su vez menor que PG (50.74 \pm 0.79$)$, siendo la mayor IS (52.09 \pm 0.05$)$; a las 48 horas fue menor en la técnica EZ (63.43 \pm 0.18$)$ en comparación con IV $(67.38 \pm 0.24)$, siendo la mayor IS (70.21 \pm 0.59$) ; y$ a las 72 horas IS $(76.52 \pm 1.12)$ fue mayor que la técnica EZ (69.12 \pm 1.36$)$; para todas las

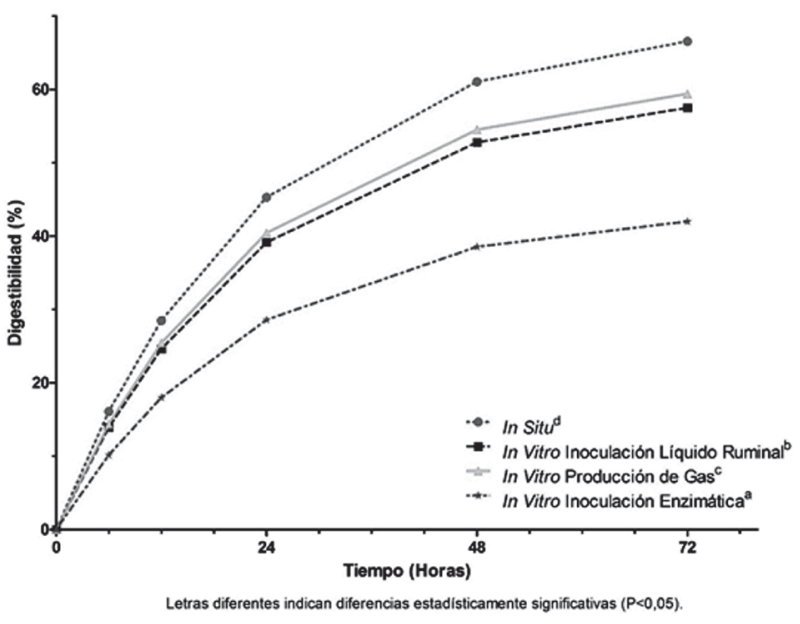

Figura 15. Digestibilidad (\%) de la proteína cruda en Gliricidia sepium estimada mediante cuatro procedimientos diferentes: in situ e in vitro: inoculación líquido numinal, producción de gas y enzimático.

demás comparaciones no hubo diferencias estadísticamente significativas entre las técnicas estudiadas en este forraje $(P>0.05)$ (Tabla 6, Figura 14).

En el tercer nutriente estudiado, las comparaciones múltiples de la digestibilidad de la PC, revelan que existen diferencias estadísticamente significativas $(\mathrm{P}<0.05)$ a las 6 horas de incubación, siendo EZ (10.17 \pm 0.98$)$ la menor de todas, seguida por IV (13.93 \pm 0.87$), y$ esta a su vez menor que en la técnica IS (16.12 \pm $3.96) ;$ a las 12 horas IS $(28.49 \pm 0.36)$ y PG $(25.45 \pm$ $0.88)$ fueron mayores que IV $(24.63 \pm 0.82)$ y ésta a su vez mayor que EZ (17.99 \pm 0.54$)$; a las 24 horas fue menor en la técnica EZ (28.60 \pm 1.30$)$, seguido por IV $(39.16 \pm 1.09)$, y luego por PG (40.45 \pm 1.52$)$, siendo la mayor IS (45.30 \pm 1.58$)$; a las 48 horas en la técnica EZ (38.54 \pm 0.24$)$ fue la menor de todas, seguida por IV (52.78 \pm 0.71$)$, siendo la mayor IS (61.06 \pm 1.64$) ; y$ se mantuvo la tendencia para las comparaciones a las 72 horas siendo la menor de todas la técnica EZ (42.00 $\pm 2.54)$, seguida por IV $(57.51 \pm 1.19)$, siendo la mayor IS (66.54 \pm 0.96$)$; para todas las demás comparaciones no hubo diferencia entre las técnicas estudiadas en el forraje $(\mathrm{P}>0.05)$ (Tabla 6, Figura 15).

La cinética de degradación de la MS fue diferente en las técnicas estudiadas, siendo mayor IS, en comparación con IV y PG, siendo a su vez mayores que EZ $(\mathrm{P}<0.05)$; por otro lado, en la FDN se observó un menor valor en la estimación EZ, seguida por IV, y esta a su vez menor que PG, siendo la mayor de todas IS $(\mathrm{P}<0,05) ; y$ de manera similar en la $\mathrm{PC}$ se observó un mayor valor en la estimación IS, seguida por PG, y esta 


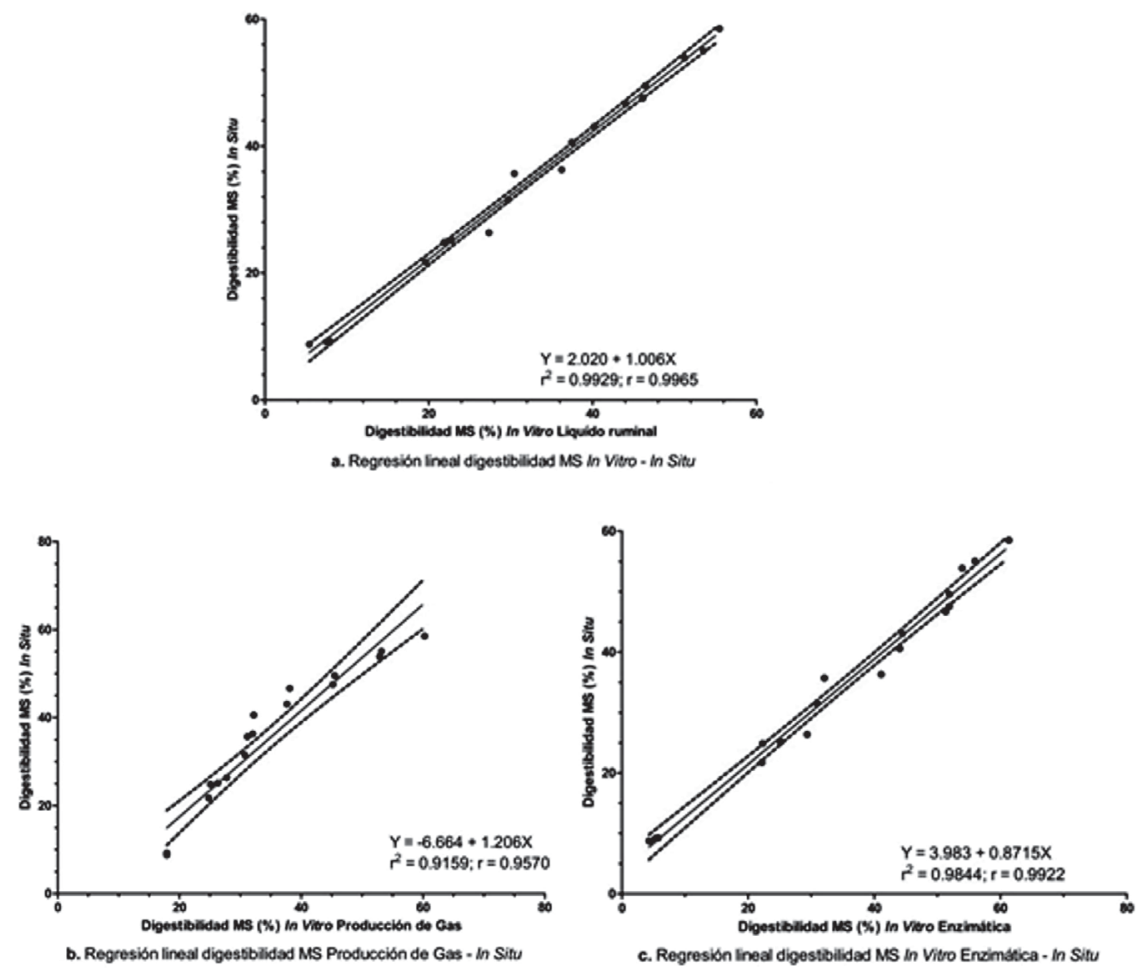

Figura 16. Regresiones lineales entre digestibilidad de la materia seca in situ y la digestibilidad de la materia seca in vitro: inóculo líquido ruminal (a), producción de gas (b) y enzimática (c) en Gliricidia sepium

Tabla 7. Regresiones lineales entre digestibilidad de la materia seca in situ (DISMS) y digestibilidad de la materia seca in vitro: inoculación liquido ruminal (DIVMS), producción de gas (DPGMS) y enzimática (DEZMS) en Gliricidia sepium

\begin{tabular}{|l|}
\hline DISMS $=2.020+1.006$ DIVMS \\
\hline DISMS $=-6.664+1.206$ DPGMS \\
\hline DISMS $=3.983+0.8715$ DEZMS \\
\hline
\end{tabular}

a su vez mayor que IV, siendo la menor EZ $(\mathrm{P}<0.05)$ (Figura 16).

La digestibilidad tanto de la MS como FDN y PC estimadas mediante las técnicas IV, PG y EZ, están altamente correlacionadas positivamente $(\mathrm{P}<0.05)$ con la digestibilidad IS, encontrando que para la primera sus valores son: (MS) $r=0.9965$, (FDN) $r=0.9982$ y (PC) $r=0.9921$; para la segunda (MS) $r=0.9570,(F D N) r$ $=0.9636$ y $(\mathrm{PC}) \mathrm{r}=0.9380$, y para la tercera $(\mathrm{MS}) \mathrm{r}=$ 0.9922, (FDN) $r=0.8221$ y (PC) $r=0.9287$; así mismo, el análisis de regresión lineal muestra la existencia de una relación entre las variables digestibilidad de la MS estimada mediante la técnica IS con respecto a la estimación IV, PG y EZ, que es explicada por las ecuaciones de la Tabla 7, en la cual es la digestibilidad (\%) de la materia seca estimada mediante la técnica in situ, en la primera ecuación es la estimación in vitro incubación con líquido ruminal; para el segundo caso es la estimación in vitro producción de gas, y para el tercer caso es la estimación in vitro enzimática (Figura 16); por lo tanto las variables digestibilidades IS de la MS, FDN y PC se explican en un $99.3\left(r^{2}=0.9929\right)$, $99.6\left(r^{2}=0.9964\right), 98.4 \%\left(r^{2}=0.9843\right)$, y $91.6\left(r^{2}=\right.$ $0.9159), 92.9\left(r^{2}=0.9285\right), 88 \%\left(r^{2}=0.8798\right)$, y 98.4 $\left(r^{2}=0.9844\right), 67.6\left(r^{2}=0.6758\right), 86.2 \%\left(r^{2}=0.8624\right)$ por la digestibilidad IV, PG y EZ respectivamente.

\section{Discusión}

Quintero et al., (1995) evaluaron los factores climáticos y altura de corte sobre el valor nutritivo y producción de materia seca del pasto Pennisetum purpureum encontrando un valor de digestibilidad in vitro de $72.2 \%$, lo cual difiere del presente estudio (39.8-44.2\%); además los autores encontraron que los factores que más afectaron esta característica fueron: precipitación, evaporación y humedad relativa, puesto que al aumentar la humedad relativa se disminuye la evaporación, con lo cual se reduce la pérdida del agua por parte de la planta, se retarda la aparición del material senescen- 
te obteniéndose un pasto por mayor tiempo verde, donde sus carbohidratos estructurales en especial la lignina están en menor grado, aumentando la digestibilidad del mismo por parte del animal. Por otro lado Nava et al., (2013) evaluaron el rendimiento y composición química del pasto Pennisetum purpureum establecido a dos densidades y en dos fechas de siembra diferentes, encontraron una digestibilidad in vitro de la materia orgánica que varió entre 62.7 y 64.9\%, valores que también resultaron mayores en comparación con lo encontrado en el presente estudio.

Kebede et al., (2016) realizaron una caracterización de la composición química y digestibilidad in vitro de la materia orgánica (materia seca menos cenizas) en Pennisetum purpureum en Etiopia, utilizando la misma metodología del presente estudio, encontraron valores que oscilaron entre 41.73-53.47\%, en función de la variedad evaluada, lo cual es más cercano a los valores encontrados en este trabajo en la digestibilidad de la materia seca (39.8-44.2\%). Tessema y Alemayehu, (2010) en investigaciones realizadas en el mismo país, encontraron valores de degradabilidad efectiva ruminal hasta las 120 horas, que oscilaron entre $51.7 \mathrm{y}$ $61.8 \%$, también superior a lo encontrado en el presente trabajo a las 72 horas $(44.2 \%)$.

Sierra et al., (2006) en una evaluación nutritiva y productiva de ovinos alimentados con heno de Hibiscus rosa-sinensis encontraron una digestibilidad de la materia seca de $76.2 \%$, lo cual fue inferior a lo encontrado en el presente estudio (79.3-84.2\%), y una digestibilidad de la FDN de $83.9 \%$, lo cual si coincide este estudio (76.3-86.9\%). Mientras que Cuéllar y Arrieta, (2010) evaluando la respuesta fisiológica en condiciones de campo y vivero, en esta misma planta discutida, encontraron valores de digestibilidad in vitro superiores a 70\%, lo cual concuerda con lo observado en este estudio. Hernández et al., (2015) estudiando la producción y calidad nutritiva del forraje para la suplementación de ovinos en pastoreo, encontraron una digestibilidad in situ de la materia seca que varió entre 91.7 a $94.1 \%$ a las 72 horas lo cual fue superior a lo encontrado en este trabajo (83.9\%); y de manera similar Izaguirre y Martínez, (2008) encontraron 71.2\% de digestibilidad de la MS. Por otro lado, Saltos, (2015) en investigaciones realizadas con Hibiscus rosa-sinensis en pollos de engorde, reporta una digestibilidad in vitro de la materia seca del $69.8 \%$, lo cual es inferior a lo encontrado en el presente estudio, aunque se trabajó con otra especie animal, lo cual afecta dicho valor.

Olivares et al., (2014) evaluando la composición química del follaje de árboles leguminosos, encontraron en Gliricidia sepium una digestibilidad de la materia seca de $32.2 \%$, lo cual fue similar a lo encontrado en este trabajo mediante la técnica enzimática (32.5\%), pero menor a lo encontrado en las otras técnicas in vitro (57.8-58.3\%), e in situ (62.1\%). Herdiawan y Sutedi, (2015) estudiando la productividad de esta misma forrajera en suelos ácidos encontraron una digestibilidad de la materia seca de $78.02 \%$, lo cual fue mayor a lo encontrado en este trabajo. Kabi y Lutakome, (2013) evaluando el efecto de la cosecha de Gliricidia sepium en diferentes frecuencias de corte en la cantidad y calidad de la biomasa para la nutrición de ganado lechero, encontraron una degradabilidad de la materia seca $(120$ h) que varió entre 54.8 y $71.6 \%$, rango que incluye los valores encontrados en este trabajo; y de manera similar Castañeda et al., (2016) reportan que la especie en la zona del Caquetá (Colombia) tiene una digestibilidad de la materia seca que oscila entre 50 y $75 \%$.

Torres et al., (2009) compararon las técnicas in situ, in vitro y enzimática (celulasa) para estimar la digestibilidad de forrajes en ovinos, quienes determinaron la digestibilidad in vitro de la materia seca (DIVMS), digestibilidad in situ de la materia seca (DISMS) y digestibilidad enzimática de la materia seca (DEMS), encontrando que la DISMS fue superior $(\mathrm{P}<0.05)$ en los cuatro forrajes estudiados con relación a la DIVMS y DEMS: 91.8 vs 73.9 y $76.5 \%$ para el rye grass de $2-4$ semanas; 74.2 vs 71.6 y 70.9 para el rye grass de 8 semanas; 77.8 vs 68.9 y 68.0 para el heno de alfalfa y 34.7 vs 29.5 y 31.7 para la paja de avena; no se observaron diferencias estadísticas entre la DIVMS y DCMS en los forrajes de mediana calidad, concluyendo que existen diferencias entre las técnicas in situ, in vitro y enzimática para estimar la digestibilidad de la materia seca del forraje en ovinos y estas diferencias dependen de la calidad del forraje.

Recientemente Vega, (2016) realizó un estudio en el cual buscó establecer el mejor método para la determinación de la digestibilidad y la determinación de la composición química de cinco pajas de mayor uso en los sistemas de producción de leche en pequeña escala del noroeste del Estado de México, encontrando una correlación positiva entre la técnica de incubación con líquido ruminal y la técnica de digestibilidad enzimática, por lo tanto el autor concluyó que no existen diferencias significativas en cuanto a la comparación de ambas técnicas $(P>0.05)$. El promedio obtenido de digestión en la técnica de incubación con líquido ruminal fue de $515 \mathrm{~g} / \mathrm{kg}$ MS en contraste a la técnica de digestibilidad enzimática en donde el resultado fue de $520 \mathrm{~g} / \mathrm{kg}$ MS. 
Posada et al., (2012) realizaron una comparación de métodos para la determinación del valor energético de alimentos para rumiantes, y en los ensayos de digestibilidad in vitro emplearon un fermentador ruminal Daisyll $\left(\right.$ ANKOM $^{\circledR}$ Technology, Macedon, New York, Estados Unidos), utilizando la metodología propuesta por Tilley y Terry, (1963) en donde la preparación del medio de cultivo y del inóculo, así como la determinación de la digestibilidad de la materia seca se basó en el protocolo propuesto por el proveedor del equipo, encontrando que hay diferencia $(\mathrm{P}<0.05)$ entre la estimación de la digestibilidad de los nutrientes totales (NDT) por los métodos in vivo e in vitro.

Mientras que González, (2016) comparó la digestibilidad de forrajes de cereales mediante el método in vitro, incubación con líquido ruminal (ANKOM Daisyll $^{\circledR}$, Macedon, New York, Estados Unidos) y enzimas (Onozuka R-10 ${ }^{\circledR}$ ), encontrando que no existen diferencias significativas $(P>0.05)$ en la digestibilidad de la MS con liquido ruminal o con enzimas (DIVMS 648.2; DEMS $644.8 \mathrm{~g} / \mathrm{kg} \mathrm{MS}$ ).

Desde otra perspectiva Noguera et al., (2011) compararon el líquido ruminal vacuno y caprino como fuente de inóculo en la técnica in vitro producción de gas, sin encontrar diferencia estadística $(P>0.05)$ entre los dos, en cuanto a la cinética de degradación de la materia seca y la materia orgánica. Durante el proceso fermentativo in vitro, los sustratos incubados con el segundo produjeron un mayor volumen de gas en relación con la cantidad de sustrato degradado, sugiriendo que una menor proporción de la materia seca degradada se utilizó para la síntesis de biomasa microbiana.

Bajo este panorama planteado, las diferencias entre las estimaciones in situ con respecto a las in vitro se han atribuido a factores como el hecho que en las primeras no hay contacto directo del líquido ruminal con el material en evaluación, por lo tanto los microorganismos deben atravesar por los poros de las bolsas para poder ejercer su acción, cobrando importancia el tamaño del poro de la bolsa, mientras que en las estimaciones in vitro utilizando tubos de ensayo, frascos o jeringas el líquido está en contacto directo y permanente con los microorganismos ruminales (Giraldo et al., 2007); otro factor que podría influir en la variabilidad de los resultados es que la microflora ruminal está influenciada por el tipo y cantidad de dieta proporcionada al animal (Torres et al., 2009). Por otro lado, las comparaciones entre las estimaciones mediante métodos enzimáticos e in situ, han arrojado una alta correlación siendo superior a 0.98 (Arce et al., 2003).
Las diferencias entre la degradabilidad in vitro e in situ pueden ser atribuidas a los procedimientos de lavado de los residuos, a exposición inadecuada de las muestras a la acción de los microorganismos por compactación del sustrato en la bolsa, o a una reducción en la actividad fibrolítica de las bacterias del rumen en las bolsas. Se esperaría que la desaparición del sustrato fuera más alta por el escape de partículas pequeñas a través de los poros de la bolsa y al efecto de la tasa de pasaje dentro del rumen, condiciones que no ocurren en la degradación in vitro; así mismo podría decirse que las diferencias entre las degradaciones in situ e in vitro $(\mathrm{P}<0,01)$ implican que hay errores en los procedimientos, o que estos dos métodos no son comparables, a pesar de existir una alta correlación entre ambos ( $r=0,87, P<0,01)$; además, las diferencias dentro de fracciones se acentúan sobre las menos solubles como FDN (Arce et al., 2003).

Se debe tener en cuenta que uno de los factores más importantes en la implementación de las técnicas in vitro está relacionado con el buffer y su preparación puesto que para ser un medio apropiado para los microorganismos del rumen, el buffer debe ser previamente saturado con $\mathrm{CO}_{2}$, para disminuir la posibilidad de aumento del potencial redox en los componentes del inóculo, es decir, disminuir los estados de oxidación de algunos de los componentes y la presencia de oxígeno; la ausencia de anaerobiosis trae como resultado la pérdida de bacterias celulolíticas y amilolíticas, lo cual disminuye notablemente la actividad de degradación dentro del inóculo, esto se traduce en una menor digestibilidad; inclusive hay evidencia de que el gaseo continuo con $\mathrm{CO}_{2}$ permite que haya una colonización del sustrato en menor tiempo y, por lo tanto, una mayor digestión de la FDN (Vargas et al., 2013); desafortunadamente en la actualidad no existen manuales que especifiquen metodologías precisas acerca de la elaboración del buffer, cómo saturarlo de $\mathrm{CO}_{2}$ y cómo comprobar que esta saturación haya quedado correctamente realizada; además la recolección del líquido ruminal es llevada a cabo de manera rustica (recipiente y trasporte), sin un protocolo establecido, lo cual permite que se genere un margen de error al realizar la práctica.

La técnica de digestibilidad enzimática, comparada con la incubación con líquido ruminal representa un menor tiempo de procesamiento, y no depende de una fuente de inóculo ruminal para simular la digestibilidad; por lo tanto, las ventajas de la técnica de digestibilidad enzimática dan respuesta a las desventajas de la técnica de digestibilidad por incubación con líquido ruminal. La técnica de digestibilidad enzimática debe ser favorecida simplemente porque la incubación con 
líquido ruminal compromete el bienestar animal del animal fistulado que se requiere como donador del inóculo (Vega, 2016); y en lo personal, hoy en día en las ciencias biológicas, es muy importante dar atención siempre al hecho de garantizar el bienestar animal.

En cuanto a las ventajas de los métodos de digestibilidad in vitro, el método de producción de gas es una alternativa versátil que se acomoda a cualquier tipo de alimento que pueda ser analizado, mientras que la técnica in situ sólo permite el análisis de alimentos de una consistencia sólida y requiere la presencia de animales con fístula ruminal para introducir los sacos de nylon; otra de las ventajas de este tipo de ensayo es la capacidad de recolección de datos por medio de métodos semiautomáticos; es decir que las presiones liberadas en los frascos de los inóculos pueden ser medidas por medio de transductores de presión, que conectados a dispositivos electrónicos pueden almacenar dicha información, dando medidas más exactas y confiables (Vargas et al., 2013).

Las especies forrajeras tropicales carecen de estudios que determinen datos específicos como la extensión y magnitud de la fermentación ruminal, la producción de gases relacionados con el efecto invernadero $\left(\mathrm{CH}_{4}\right)$, así como su digestibilidad, factores que no han permitido la determinación real de su valor nutricional, por tanto la técnica in vitro es una herramienta de vital importancia para las ciencias agropecuarias, al estimar la capacidad de degradación de los forrajes que componen la dieta de las especies ovinas, caprinas y bovinas del país, que son fuente de proteína para las poblaciones humanas en las diferentes regiones del mundo (Vargas et al., 2013).

\section{Conclusiones}

Se puede inferir que las técnicas in vitro para estimar la digestibilidad en rumiantes son una herramienta de gran importancia en el bioensayo, dada la facilidad para desarrollarla, costos reducidos, aplicación en el ámbito local, información valiosa que aporta, teniendo en cuenta que son escasos los estudios sobre la digestibilidad in vitro de forrajes tropicales en la zona del piedemonte llanero colombiano.

Se analizó la curva y tasa de degradación de la materia seca (MS), fibra detergente neutro (FDN) y proteína cruda (PC) a las 0, 6, 12, 24, 48 y 72 horas, en las especies forrajeras: Pennisetum purpureum (PP), Hibiscus rosa-sinensis (HR) y Gliricidia sepium (GS) mediante cuatro técnicas diferentes: in situ e in vitro: inoculación líquido ruminal, producción de gas y enzimática, la cual varió entre 39.89-44.22, 54.18-64.26 у $47.54-57.05 \% ; 79.29-84.18,76.30-86.95$ у 72.81$89.03 \%$; 32.52-62.14, 69.12-76.52 y $42.00-66.54 \%$ respectivamente en los forrajes PP, HR y GS, en la MS, FDN y PC, en función de la técnica empleada para su estimación; y a pesar de encontrar diferencias estadísticamente significativas $(\mathrm{P}<0.05)$ entre varias de las comparaciones realizadas en los procedimientos, se encontró un alto coeficiente de determinación y alta correlación entre las estimaciones in vitro: inoculación con líquido ruminal, producción de gas y enzimática con respecto a la estimación in situ, siendo la más practica la enzimática.

\section{Agradecimientos}

Los autores agradecen a la Dirección General de Investigaciones (DGI) de la Universidad de los Llanos por el apoyo financiero (Proyecto Código: C04F01-008-2015).

\section{Referencias}

Araujo FO, Vergara LJ. Propiedades físicas y químicas del rumen, Arch Latinoam Prod Anim. 2007;15(Supl.1):133-140. [Fecha de acceso: 2017, November 04], Disponible En: http://www.bioline.org.br/pdf?la07044.

Arce C, Arbaiza T, Carcelén F, Lucas O. Estudio comparativo de la digestibilidad de forrajes mediante dos métodos de laboratorio. Rev Investig Vet. Perú. 2003;14 (1):7-12.

Beuvink J, Spoelstra S, Hogendorp R. An automated method for measuring time-course of gas production of feed-stuffs incubated with buffered rumen fluid. NJAS. 1992;40:401-401.

Botero L, Gómez R. Uso de animales de laboratorio en Colombia: reflexiones sobre aspectos normativos y éticos. Rev Med Vet Zoot. 2013;60(3):213-219.

Bulang M, Elwert C, Spilke J, Rodehutscord M. Suitability of synthetic alkanes as markers for the estimation of passage rate in sheep. Livest Sci. 2008;115 (1): 42 - 52.

Cardozo J. 2013. El matarraton (Gliricidia sepium) en la alimentación de rumiantes, Especialista en Nutrición Animal Sostenible. Universidad Nacional Abierta y a Distancia, Bogotá, Colombia. 65 pp.

Castañeda NP, Álvarez F, Arango J, Chanchy L, García GF, Sánchez V, Solarte A, Sotelo M, Zapata C. 2016. Especies vegetales útiles para sistemas silvopastoriles del Caquetá, Colombia. Centro Internacional de Agricultura Tropical (CIAT), Cali, Colombia. 84 pp.

Concepción ÁR, De la Peña R, García J. Acercamiento al accionar ético-moral del científico que trabaja con animales de experimentación. Acta Bioeth. 2007;13 (1):9-15.

Cuéllar ND, Arrieta JM. Evaluación de respuestas fisiológicas de la planta arbórea Hibiscus rosasinensis L,(Cayeno) en condiciones de campo y vivero. Corpoica Cienc Tecnol Agropecu. 2010;11(1):61-72. 
Davies Z, Mason D, Brooks A, Griffith G, Merry R, Theodorou M. An automated system for measuring gas production from forages inoculated with rumen fluid and its use in determining the effect of enzymes on grass silage. Anim Feed Sci Technol. 2000;83(3-4):205-221.

De Osorio AM. Ética en la investigación con modelos animales experimentales. Alternativas y las 3 RS de Russel. Una responsabilidad y un compromiso ético que nos compete a todos. Revista Colombiana de Bioética. 2006;1(1):163-183.

Duarte F, Castro G, Gutiérrez E, Tena J. Engorda de toretes con ensilaje de estiércol de cerdo con melaza y paja de sorgo y suplementos proteinicos. LRRD; 2000;12(3):Article 26.

Estupiñán K, Vasco D, Duchi N. Digestibilidad de los componentes de la pared celular del forraje de Canavalia ensiformis (L) DC. en diferentes edades de corte. Revista Tecnológica-ESPOL. 2007;20(1):223-228.

Giraldo L, Gutiérrez LA, Rúa C. Comparación de dos técnicas in vitro e in situ para estimar la digestibilidad verdadera en varios forrajes tropicales. Rev Colomb Cienc Pec. 2007;20(3):269-279.

Gómez JM, Yepes SA, Barahona R. Caracterización nutricional del residuo del cultivo de la seta Agaricus bisporus como alimento potencial para bovinos. Revista CES Medicina Veterinaria y Zootecnia. 2013;8(1):34-56.

González FA. 2016. Comparación de la digestibilidad in vitro, mediante la incubación con líquido ruminal o enzimática en forrajes de cereales de grano pequeño en sistemas de producción de leche en pequeña escala, Médico Veterinario Zootecnista. Facultad de Medicina Veterinaria y Zootécnia, Universidad Autónoma del Estado de México, Toluca, México. 46 pp.

Herdiawan I, Sutedi E. Productivity of Calliandra calothyrsus, Indigofera zollingeriana and Gliricidia sepium on acid soil in the Greenhouse. IJAVS. 2015;20 (2):105-114.

Hernández D, Pinto R, Aranda EM, Mata MÁ, Hernández G, Cruz A, Ramírez E, Hernández O, Coutiño PR. Producción y calidad nutritiva de los forrajes de morera Morus alba y tulipán Hibiscus rosa-sinensis para la suplementación de ovinos en pastoreo. Quehacer Cient Chis. 2015;10(1):29-39.

IDEAM, Instituto de Hidrología, Meteorología y Estudios Ambientales. 2014. Información Histórica, Climatografía de las principales ciudades, Cartas Climatológicas - Medidas Mensuales, Aeropuerto Vanguardia. [Fecha de acceso: 25 Sep 2015], Disponible En: http:bart.ideam.gov.co/cliciu/villavo/tabla.htm.

Izaguirre F, Martínez JJ. El uso de árboles multipropósito como alternativa para la producción animal sostenible. Tecnología en marcha. 2008;21(1):28-40.

Kabi F, Lutakome P. Effect of harvesting Gliricidia sepium at different cutting frequencies on quantity and quality of herbage biomass for dairy cattle nutrition. J Anim Sci Adv. 2013;3(6):321-336.

Kebede G, Feyissa F, Assefa G, Alemayehu M, Mengistu A, Kehaliew A, Melese K, Mengistu S, Tadesse E, Wolde S. Chemical Composition and In-vitro Organic Matter Digestibility of $\mathrm{Na}$ pier Grass (Pennisetum purpureum (L.) Schumach) Accessions in the Mid and Highland Areas of Ethiopia. Int J Livest Res. 2016;6(4):41-59.
Menke K, Raab L, Salewski A, Steingass H, Fritz D, Schneider W. The estimation of the digestibility and metabolizable energy content of ruminant feedingstuffs from the gas production when they are incubated with rumen liquor in vitro. J Agr Sci. 1979;93(1):217-222.

Mertens DR. Gravimetric determination of amylase-treated neutral detergent fiber in feeds with refluxing in beakers or crucibles: collaborative study. Journal of AOAC international. 2002;85(6):1217-1240.

Muro R. 2007. Cinética de degradación ruminal de tres fuentes de forraje mediante la técnica de digestibilidad in vitro por producción de gas, Tesis Doctorado. Universidad autonoma, Chihuahua, México. pp.

Nava J, Gutiérrez E, Herrera RS, Zavala F, Olivares E, Treviño J, Bernal $H$, Valdés C. Rendimiento y composición química del pasto CT-115 (Pennisetum purpureum) establecido a dos densidades y en dos fechas de siembra en Marín, Nuevo León, México. Rev Cubana Cien Agric. 2013;47(4):419-424.

Noguera R, Ortiz D, Gallego N. Comparación de líquido ruminal vacuno y caprino como fuente de inóculo en la técnica in vitro de producción de gases. Livest Res Rural Dev. 2011;23(11):Art \# 225.

Olivares J, Avilés F, Albarrán B, Rojas S, Córdova A, Villa A, Castelán O. Chemical composition of leguminous tree foliage and effect of polyethylene glycol on gas production and in vitro digestion parameters. Trop Subtrop Agroecosyst. 2014;17(2):207-214.

Pell A, Schofield P. Computerized monitoring of gas production to measure forage digestion in vitro. J Dairy Sci. 1993;76(4):10631073.

Posada SL, Solano RN, Rodríguez NM, Costa A. Comparación de métodos para la determinación del valor energético de alimentos para rumiantes. Revista MVZ Córdoba. 2012;17(3):31843192.

Quintero B, Clavero T, Castro C, del Villar A, Araujo O. Efecto de los factores climáticos y altura de corte sobre el valor nutritivo y producción de materia seca del pasto elefante enano (Pennisetum purpureum Schum. cv. Mott). Rev Fac Agron. 1995;12(1):81-94.

Rincón Á, Bueno G, Mauricio Á, Pardo O, Pérez O, Caidedo S. 2010. Establecimiento, manejo y utilización de recursos forrajeros en sistemas ganaderos de suelos ácidos CORPOICA (Corporación Colombiana de Investigación Agropecuaria), Villavicencio, Meta, Colombia. 251 pp.

Sainz RA. 2016. Comparación de dos metodos in vitro para estimar la digestibilidad de ensilados de maíz (Zea mays) de sistemas de producción de leche en pequeña escala, Médico Veterinario Zootecnista. Facultad de Medicina Veterinaria y Zootecnia, Universidad Autónoma del Estado de México, Toluca, México. 39 pp.

Saltos JC. 2015. Niveles de harinas de cucarda (hibiscus rosa-sinensis) y maní forrajero (arachis pintoi) en la alimentación de pollos organicos, finca la María, Mocache-Ecuador, Ingeniero Zootecnista. Facultad de Ciencias Pecuarias. Carrera de Inge- 
nieria Zootecnica, Universidad Técnica Estatal de Quevedo, Quevedo, Ecuador. 59 pp.

Sierra ÁC, Aguilar E, Magaña MA, Sanginés JR, Lara PE. Evaluación nutritiva y productiva de ovinos alimentados con heno de $\mathrm{Hi}$ biscus rosa-sinensis. Zootec Trop. 2006;24 (4):467-482.

Sosa D, Larco C, Falconí R, Toledo D, Suárez G. Digestibilidad de maralfalfa (Pennisetum sp.) en cabras, Bol Téc Ser Zool. 2006;5(2):68-76. [Fecha de acceso: 03 October 2017], Disponible En: https://www.engormix.com/ovinos/articulos/digestibilidad-maralfalfa-pennisetum-cabras-t27114.htm.

Tessema Z, Alemayehu M. Management of napier grass (Pennisetum Purpureum (L.) Schumach) for high yield and nutritional quality in Ethiopia: A Review. Ethiopian Journal of Animal Production. 2010;10(1):73-94.

Theodorou MK, Williams BA, Dhanoa MS, McAllan AB, France J. A simple gas production method using a pressure transducer to determine the fermentation kinetics of ruminant feeds. Anim Feed Sci Technol. 1994;48(3-4):185-197.

Tilley J, Terry R. A two-stage technique for the in vitro digestion of forage crops. Grass Forage Sci. 1963;18(2):104-111.
Torres G, Arbaiza T, Carcelén F, Lucas O. Comparación de las técnicas in situ, in vitro y enzimática (celulasa) para estimar la digestibilidad de forrajes en ovinos. Revista de Investigaciones Veterinarias del Perú, RIVEP. 2009;20(1):5-9.

Uffo O. 2011. Producción animal y biotecnologías pecuarias: nuevos retos. Revista de Salud Animal. 33 (1): 08-14.

Valencia L, Restrepo J, Cerón DE, Herrera WF. Determinación de la digestibilidad in vivo en ovinos utilizando dietas a base de forrajes tropicales. Revista de Investigación Agraria y Ambiental, RIAA. 2010;1(1):25-29.

Vargas JE, Mejía GP, Bedoya JM, Gómez JF. Estimación de la técnica in vitro de gases frente a otras técnicas de digestibilidad. Spei Domus. 2013;9(18):59-70.

Vega JI. 2016. Determinación de la digestibilidad in vitro de pajas mediante dos métodos: incubación con líquido ruminal y digestibilidad enzimática, Médico Veterinario Zootecnista. Facultad de Medicina Veterinaria y Zootecnia, Universidad Autónoma del Estado de México, Toluca, México. 46 pp.

Waghorn G, Stafford K. Gas production and nitrogen digestion by rumen microbes from deer and sheep. New Zeal J Agr Res. 1993;36(4):493-497. 